\title{
Metabolic engineering strategies for butanol production in Escherichia coli
}

\author{
Sofia Ferreira $^{1,2} \mid$ Rui Pereira ${ }^{3,4} \mid$ S. A. Wahl $\left.\right|^{5} \mid$ Isabel Rocha ${ }^{1,2}$ (c) \\ ${ }^{1}$ CEB-Centre of Biological Engineering, University of Minho, Campus de Gualtar, Braga, Portugal \\ ${ }^{2}$ Instituto de Tecnologia Química e Biológica António Xavier, Universidade Nova de Lisboa (ITQB-NOVA), Oeiras, Portugal \\ ${ }^{3}$ SilicoLife Lda, Braga, Portugal \\ ${ }^{4}$ Department of Biology and Biological Engineering, Chalmers University of Technology, Gothenburg, Sweden \\ ${ }^{5}$ Department of Biotechnology, Delft University of Technology, Delft, The Netherlands
}

\section{Correspondence}

Isabel Rocha, CEB-Centre of Biological

Engineering, University of Minho, Campus de

Gualtar, 4710-057 Braga, Portugal.

Email: irocha@itqb.unl.pt

Present address

Sofia Ferreira, Instituto de Tecnologia Química e Biológica António Xavier, Universidade Nova de Lisboa (ITQB-NOVA), Oeiras, Portugal.

Funding information

Ministério da Ciência, Tecnologia e Ensino Superior, Grant/Award Number: ERA-IB-2/ 0002/2014; Fundação para a Ciência e a Tecnologia, Grant/Award Numbers: ERA-IB-2/

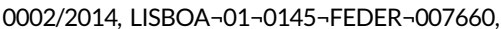
$\mathrm{PD} / \mathrm{BD} / 52366 / 2013$; European Commission, Grant/Award Number: H2020-LEIT-BIO-2015-1 686070-1

\begin{abstract}
The global market of butanol is increasing due to its growing applications as solvent, flavoring agent, and chemical precursor of several other compounds. Recently, the superior properties of $n$-butanol as a biofuel over ethanol have stimulated even more interest. (Bio)butanol is natively produced together with ethanol and acetone by Clostridium species through acetone-butanol-ethanol fermentation, at noncompetitive, low titers compared to petrochemical production. Different butanol production pathways have been expressed in Escherichia coli, a more accessible host compared to Clostridium species, to improve butanol titers and rates. The bioproduction of butanol is here reviewed from a historical and theoretical perspective. All tested rational metabolic engineering strategies in E. coli to increase butanol titers are reviewed: manipulation of central carbon metabolism, elimination of competing pathways, cofactor balancing, development of new pathways, expression of homologous enzymes, consumption of different substrates, and molecular biology strategies. The progress in the field of metabolic modeling and pathway generation algorithms and their potential application to butanol production are also summarized here. The main goals are to gather all the strategies, evaluate the respective progress obtained, identify, and exploit the outstanding challenges.
\end{abstract}

\section{KEYWORDS}

biofuels, butanol, Escherichia coli, genome-scale metabolic models, metabolic engineering

\section{1 | INTRODUCTION}

The history of butanol dates back to 1861, when Louis Pasteur first described the production of butanol by microorganisms, under anaerobic conditions (Pasteur, 1862). The French microbiologist detected butanol in a culture of, what he called, Vibrion butyrique, presumably a mixed-culture containing clostridia species (Dürre, 2008). These strains can convert carbohydrates into solvents, through the Acetone-Butanol-Ethanol (ABE) fermentation. During World War I, the industrial interest on ABE fermentation had emerged mainly due to the interest in acetone, since high amounts of this compound were needed to produce cordite (Buehler \& Mesbah, 2016; Dürre, 2007; García, Päkkilä, Ojamo, Muurinen, \& Keiski, 2011; Ndaba, Chiyanzu, \& Marx, 2015). Coincidently, Chaim Weizmann had isolated a strain of, later known as, Clostridium acetobutylicum able to produce acetone, $n$-butanol and ethanol in a ratio of 3:6:1 from 
starch and sugars and applied for a patent in 1915 (4845, 1919) $N$-Butanol's initial role as an unwanted by-product in the $A B E$ fermentation process changed when its potential as a bulk chemical gained attention with the rapidly growing need for quick-drying lacquers for the automobile industry (Sauer, 2016). However, the appearance of a new chemical process for the production of butanol based on propylene oxo synthesis led to the decline of $A B E$ fermentation because fermentation could no longer compete with the petrochemical process (Dürre, 2008; García et al., 2011; Green, 2011). For this reason, synthetic butanol costs are linked to the propylene market and are sensitive to the price of crude oil (Green, 2011). The recent instability of crude oil prices led to the reestablishment of some butanol producing plants in China and Brazil (Pfromm, Amanor-Boadu, Nelson, Vadlani, \& Madl, 2010).

There are four isomeric forms of butanol: $n$-butanol or 1-butanol, sec-butanol or 2-butanol, isobutanol and tert-butanol. Currently, most of the attention given to $n$-butanol comes from its application as a (bio) fuel. Isobutanol has also interesting properties as a biofuel due to its high blending octane number and some authors have explored its production in yeast (Park \& Hahn, 2019; Wess, Brinek, \& Boles, 2019) or in Escherichia coli, Bacillus subtilis, and Corynebacterium glutamicum (Blombach \& Eikmanns, 2011). The two remaining isomers are less explored and are mostly used as solvents. Sec-butanol is naturally produced from meso-2,3-butanediol in Lactobacillus diolivorans (Russmayer, Marx, \& Sauer, 2019), while tert-butanol is not directly produced by fermentation (Viswanath, 2019). To be competitive in the fuel market, the bioprocesses available for butanol production need to be engineered to decrease the cost of the final product (Jang, Malaviya, Cho, Lee, \& Lee, 2012). This review resumes the overall challenges of producing n-butanol with the native producers, but mostly focuses in the metabolic engineering (ME) strategies to produce $n$-butanol in E. coli, a more industrially robust microorganism.

\section{2 | BUTANOL PRODUCTION VIA ABE FERMENTATION}

The $A B E$ fermentation occurs naturally in microorganisms from the Clostridium genus. Clostridium spp. are rod-shaped, Gram-negative, strict anaerobes, spore-forming bacteria (Ndaba et al., 2015). Clostridial species differ in their ability to ferment various substrates, the patterns of solvent ratios and some diversity of chemicals produced (Patakova, Linhova, Rychtera, Paulova, \& Melzoch, 2013). Particularly, C. acetobutylicum and Clostridium beijerinckii are the best-studied species and most applied for industrial production of butanol. The maximum titer of butanol is usually $<13 \mathrm{~g} / \mathrm{L}$ during batch fermentation since butanol is highly toxic to the cells (Visioli, Enzweiler, Kuhn, Schwaab, \& Mazutti, 2014). The ABE fermentation is a biphasic process, comprising an acidogenic and a solventogenic phase. During the acidogenesis, the cells ferment sugar or starch into butyrate, acetate, carbon dioxide, and hydrogen, which lowers the $\mathrm{pH}$ of the medium. At the end of the exponential phase, a metabolic shift takes place in clostridial strains and the solventogenic phase starts: the previously excreted acids are reassimilated and converted in neutral solvents such as acetone, butanol, and ethanol (Dürre, 2008). Nevertheless, the solvents (mainly butanol) damage the cells by inactivating membrane proteins and disrupting the membrane. In parallel to the solventogenic phase, cells start to form endospores, which guarantee a long-term survival. Thus, the solventogenic and sporulation regulatory networks are correlated.

Despite the long history of using Clostridium species to perform $A B E$ fermentation, some challenges remain nowadays, namely: (a) the sensitivity of clostridial strains to the inhibitors from lignocellulosic feedstocks (b) the low productivity of butanol due to the long fermentation times (c) high costs in downstream processing due to the production of other solvents; (d) phenotypic instabilities; (e) low tolerance to butanol; (f) lack of efficient genome engineering tools; (g) the complex regulatory and metabolic networks (Pfromm et al., 2010; Visioli et al., 2014). Many lines of research are currently being followed to improve butanol production in the natural host by addressing the mentioned issues, and a review of the main findings has been published (Sauer, 2016).

The achieved progress and the remaining challenges are summarized as it follows. The conversion of cheap lignocellulosic substrates into butanol is important to achieve an economically feasible process. However, clostridial strains are more sensitive to the inhibitors resultant from the pretreatment processes when compared with other microorganisms. Efforts have been made to develop methodologies for removal of these inhibitors, but the productivities obtained by converting lignocellulosic substrates are still low (Jang et al., 2012). The low productivity of butanol in ABE fermentation due to the long fermentation times can be alleviated by continuous cultures. Nevertheless, the implementation of continuous cultures using clostridial strains has shown to be difficult due to the loss of the solvent production phenotype over time and the two-stage fermentation. In this regard, semicontinuous reactors and immobilized systems have shown higher productivities when compared with batch cultures (Green, 2011; Visioli et al., 2014). Also, the production of byproducts and the low volumetric solvent productivity in $A B E$ fermentation lead to high costs in the recovery process. For the recovery of butanol from the fermentation broth, researchers suggest techniques such as adsorption, liquid-liquid extraction, gas stripping, and pervaporation. The in situ application of some of these processes can help alleviating butanol toxicity issues (Dürre, 2007; Visioli et al., 2014) Lastly, the lack of efficient synthetic biology tools to edit microorganisms from genus Clostridium hinders the application of $\mathrm{ME}$ strategies. The main issues are the low efficiency of DNA transformation (below $10 \mathrm{CFU} / \mu \mathrm{g}$ ), endonuclease activity, the requirement for a robust selective marker and the lack of a stable shuttle plasmid available (Joseph, Kim, \& Sandoval, 2018; Yan \& Fong, 2017). The advent of new genome-editing strategies, particularly of the CRISPRCas9 system, has facilitated strain engineering for several microorganisms and, simultaneously, enlarged the range of applications (Tian et al., 2017). Nevertheless, the complex regulatory and metabolic mechanisms of clostridial strains hinder the development of better cell factories. 
Despite the active research in these topics and the progress obtained so far, some of the challenges described above are Clostridium-specific and can be overcome by producing butanol in other hosts with features more suitable with the industrial requirements. The first attempt to produce butanol in an nonnative producing microorganism was in Saccharomyces cerevisiae, achieving a very modest titer of $2.5 \mathrm{mg} / \mathrm{L}$ (Steen et al., 2008). More recently, a higher titer of $0.86 \mathrm{~g} / \mathrm{L}$ was achieved by increasing acetyl-CoA and NADH levels (Schadeweg \& Boles, 2016). Other microorganisms such as the cyanobacteria Synechococcus elongatus PCC 7942 (Lan \& Liao, 2012) and the bacteria Pseudomonas putida and B. subtilis (Nielsen et al., 2009) were also engineered to produce butanol. However, the most progress on improving butanol production has been made in E. coli. E. coli has shown to be the most promising host to produce this compound achieving butanol titers as high as $30 \mathrm{~g} / \mathrm{L}$. Although some issues remain to be solved (see future perspective section), the status of $E$. coli as industrial workhorse, as well as the compatibility of its anaerobic metabolism with butanol production makes it one of the most engineered hosts for producing this compound.

\section{3 | RECOMBINANT BUTANOL PRODUCTION IN E. COLI}

E. coli is a Gram-negative, rode-shaped, facultative anaerobic bacterium, physiologically, and genetically well-characterized with plenty of efficient genetic tools available. The large knowledge about its genetic, metabolic and physiological characteristics enables its engineering for the production of diverse target compounds. Moreover, E. coli possesses several industrially relevant characteristics like (a) capacity to grow on mineral media, (b) utilization of different substrates as carbon source, (c) fast growth rate, (d) ability to grow under aerobic and anaerobic conditions, (e) robustness under industrial conditions, and ( $f$ ) tolerance to high concentrations of substrates and products (Clomburg \& Gonzalez, 2010; Koppolu \& Vasigala, 2016). Hence, E. coli has been successfully engineered for the production of diverse products, including hormones (Rezaei \& Zarkesh-Esfahani, 2012), proteins (Reyes, Cardona, Pimentel, Rodríguez-López, \& Alméciga-Díaz, 2017), and amino acids (Lee, Park, Kim, Kim, \& Lee, 2007; Park, Lee, Kim, \& Lee, 2007). Particularly, its potential to produce biofuels was first explored with ethanol, a native product (Ohta, Beall, Mejia, Shanmugam, \& Ingram, 1991).

In 2008, Atsumi et al. described for the first time the production of butanol in E. coli (Atsumi et al., 2008). In this study, the genes constituting the clostridial butanol biosynthetic pathway (thl, crt, hbd, bcd-etfAB, adhE) were expressed in E. coli. The maximum butanol titer achieved was $0.552 \mathrm{~g} / \mathrm{L}$, obtained by replacing thl by the native gene $a t o B$ and cultivating cells semiaerobically in terrific broth (TB) supplemented with $2 \%$ glycerol. Considering that Clostridium strains are able to produce butanol titers up to $20 \mathrm{~g} / \mathrm{L}$, the recombinant butanol production in $\mathrm{E}$. coli needed further optimization to compete with the native producers (Figure 1).

\section{4 | RATIONAL DESIGN STRATEGIES TO IMPROVE RECOMBINANT BUTANOL PRODUCTION IN E. COLI}

Since the first reported recombinant butanol production in E. coli, several authors have tried to increase butanol titers. To do so, various rational strategies have been designed and implemented. In Figures 2-4, the main attempts to improve butanol production in E. coli are summarized.
FIGURE 1 The combination of the depletion of natural resources and the increasing environmental awareness with the development of the metabolic engineering field have stimulated the rational design of microbial cell factories to produce biofuels like butanol. These microbial cell factories can convert renewable substrates into target metabolites replacing chemical-based processes [Color figure can be viewed at wileyonlinelibrary.com]

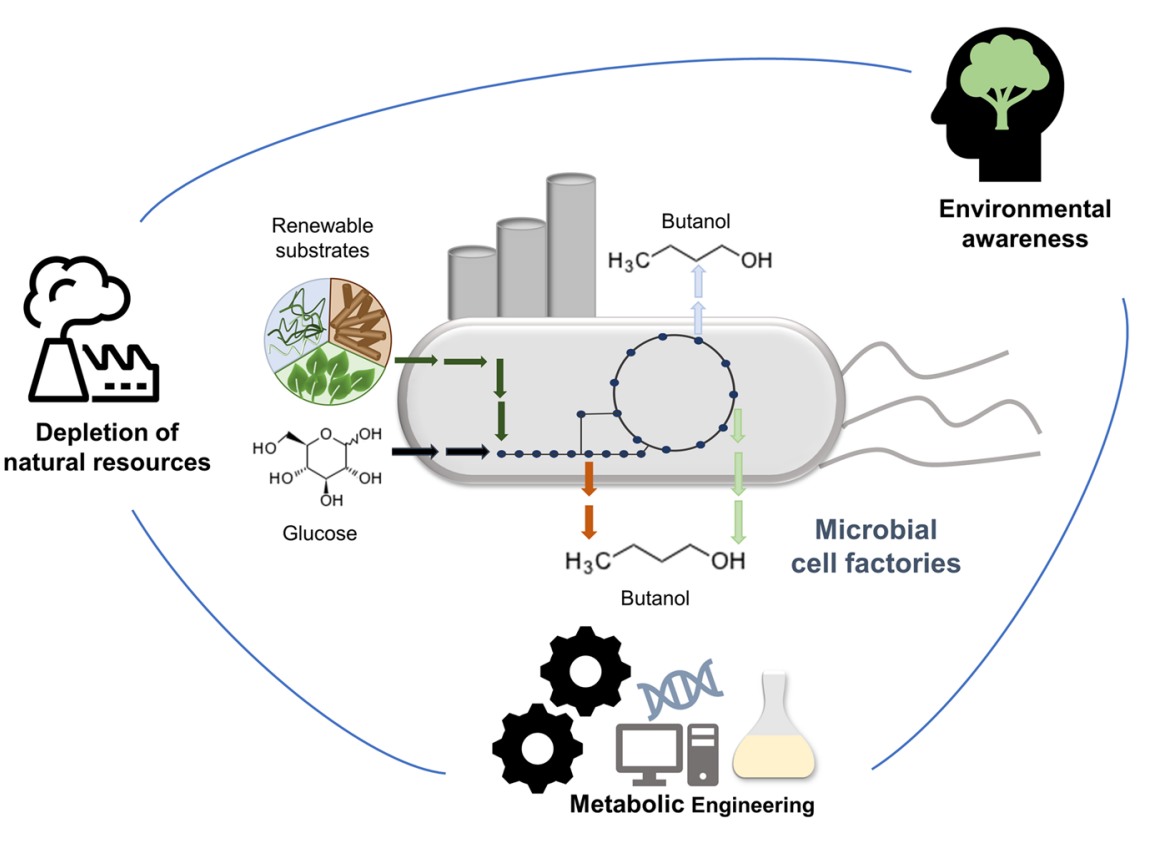




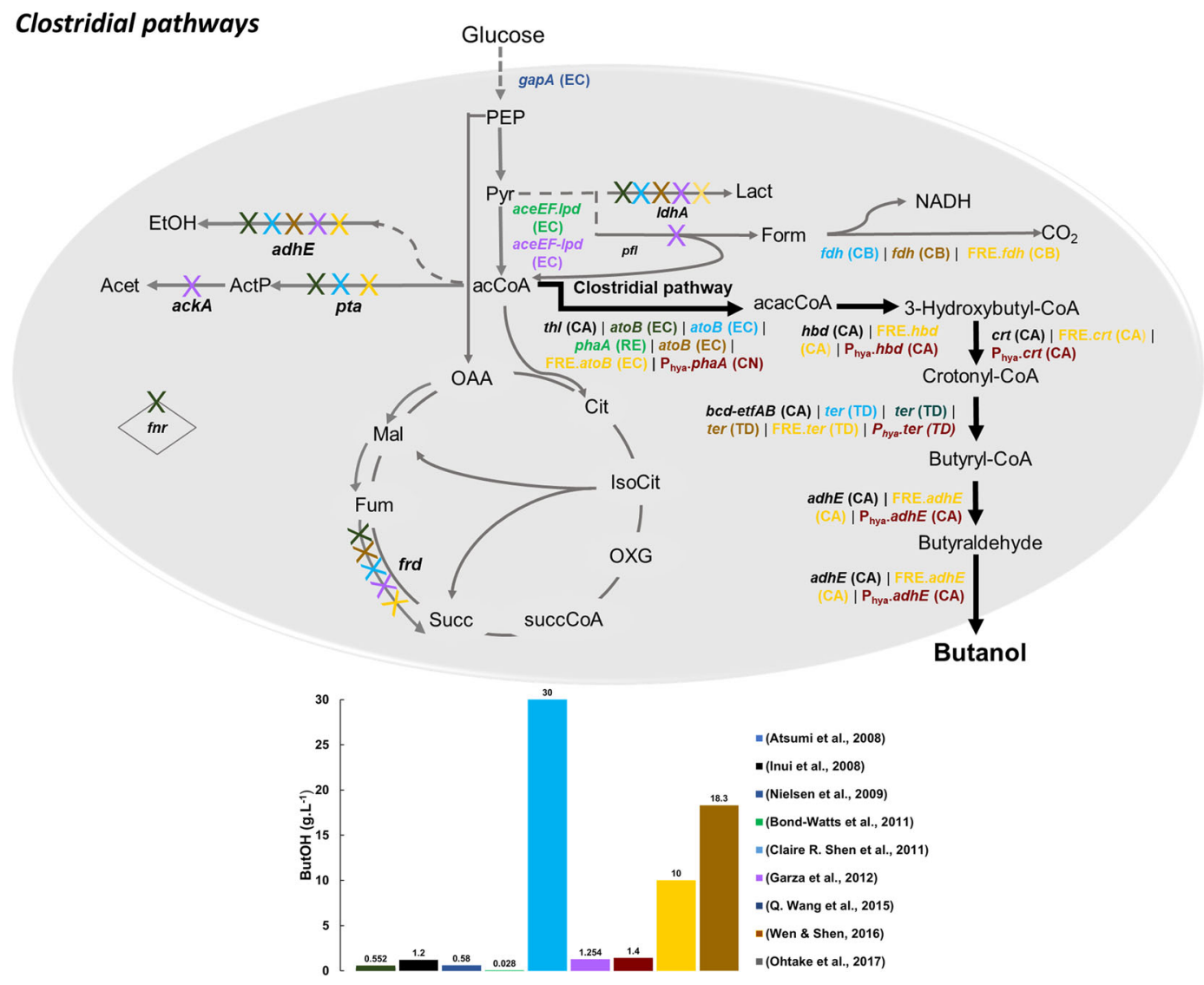

FIGURE 2 Schematic overview of the different strategies reported in the literature to produce butanol in Escherichia coli using variations of the clostridial pathway. Besides the alternative pathways to produce butanol, the genetic strategies to improve butanol production are also depicted. For each group of strategies tested in each reference, only the best butanol producing combination is shown. The $n$-butanol synthetic pathway from Clostridium acetobutylicum is represented with black arrows, for each strategy only the alternative catalytic steps/enzymes are shown. Alternatives described in the literature to this pathway including gene knockout, overexpression, different substrates are highlighted in the respective color. Dashed lines represent successive enzymatic reactions; $X$ indicates gene knockouts; diamonds correspond to transcriptional regulators. acacCoA, acetoacetyl-CoA; acCoA, acetyl-CoA; Acet, acetate; ActP, acetyl-phosphate; CA, Clostridium acetobutylicum; CB, Candida boidinii; Cit, citrate; EC, Escherichia coli; EtOH, ethanol; Form, formate; FRE, fermentation regulatory elements; Fum, fumarate; Isocit, isocitrate; Lact, lactate; Mal, malate; OAA, oxaloacetate; OXG, 2-oxoglutarate; PEP, phosphoenolpyruvic acid; Pyr, pyruvate; RE, Ralstonia eutropha; Succ, succinate; succCoA, succinyl-CoA; TD, Treponema denticola [Color figure can be viewed at wileyonlinelibrary.com]

By analyzing Figures $2-4$, it is possible to perceive a variety of strategies to produce butanol in E. coli, including: manipulation of the central carbon metabolism either by gene disruption or gene overexpression, conversion of different substrates, testing different enzymes for specific steps of the clostridial pathway, or expression of alternative biosynthetic pathways. Most of the strain designs focused on the expression of the clostridial pathway and respective derivatives. Nevertheless, four new routes were also explored: the reversed $\beta$-oxidation cycle, the keto-acids pathway, the acyl-acyl carrier protein-dependent pathway and the oxoglutarate pathway (Figure 3).

Within the strain designs depicted in Figures 2-4, a variety of titers was obtained ranging from $9 \times 10^{-4}$ to $30 \mathrm{~g} / \mathrm{L}$. It is also possible to see that the first and fourth steps of the clostridial pathway are the ones where more alternative enzymes have been tested. Regarding gene knockouts, the genes responsible for the production of ethanol ( $a d h E)$, succinate ( $f r d A B C D)$, acetate (pta-ackA), and lactate $(I d h A)$ are the most common targets. Particularly, the gene responsible for the production of ethanol was knocked-out in nine out of the 17 strategies shown in Figures 2-4.

The titers obtained also depend on the strain of $E$. coli used as host, culture medium used and cultivation conditions. For this reason, the details for each genetic engineering strategy depicted in Figures 2-4 are shown in Table 1, including the culture conditions and host strains used.

Overall, within the published works shown in Table 1, the medium most used is the complex medium TB or mineral media supplemented with complex nutrients like yeast extract. In fact, the presence in the medium of complex nutrients seems to be beneficial for butanol production through clostridial pathway and its derivatives. By removing complex nutrients such as tryptone and yeast extract from the medium, some authors observed a reduction in butanol production (Shen et al., 2011; Wen \& Shen, 2016). The authors have suggested that the presence of complex nutrients may be beneficial due to the metabolic burden imposed when expressing 


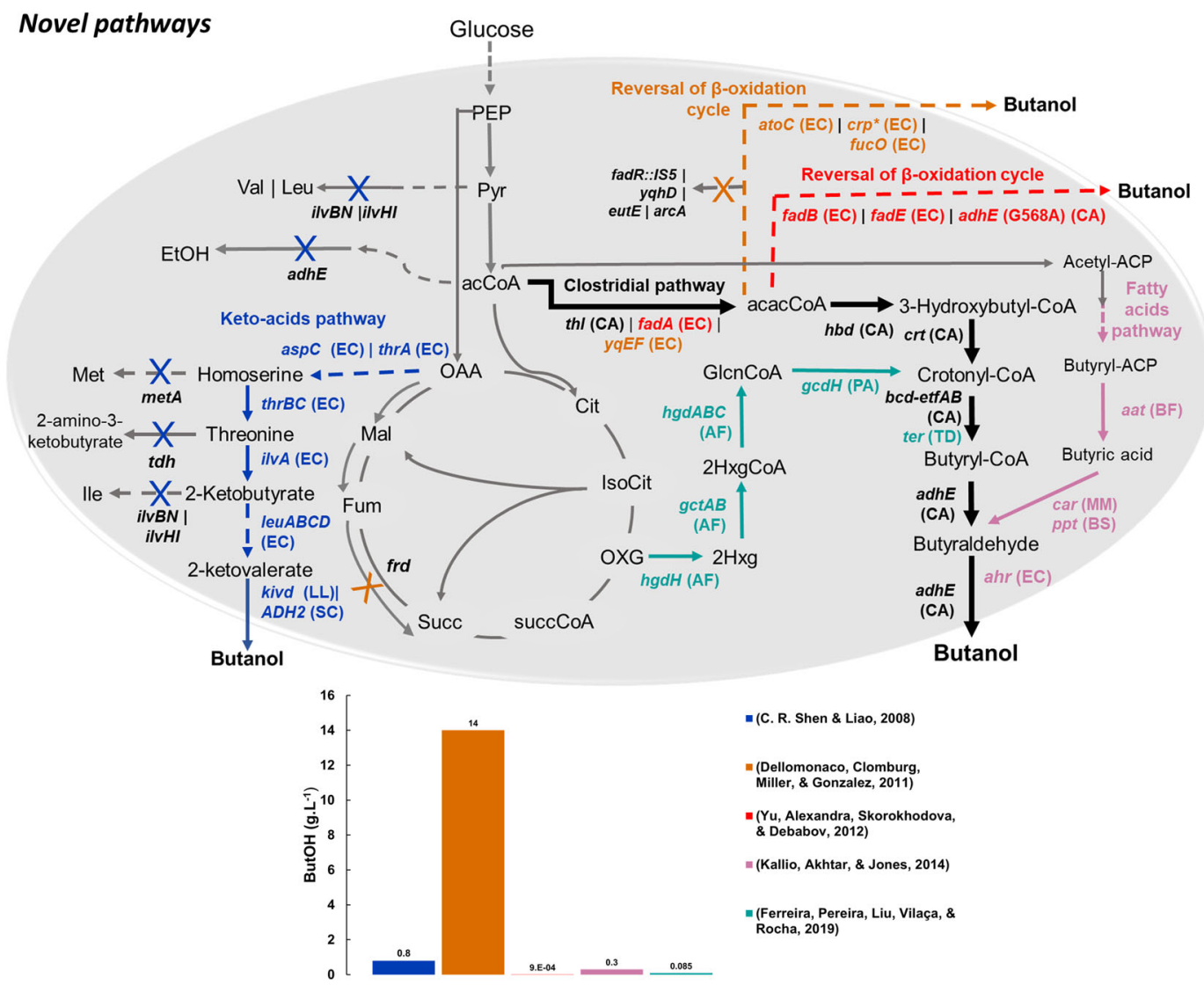

FIGURE 3 Schematic overview of the different strategies reported in the literature to produce butanol in Escherichia coli through novel pathways. Besides the alternative pathways to produce butanol, the genetic strategies to improve butanol production are also depicted. For each group of strategies tested in each reference, only the best butanol producing combination is shown. The $n$-butanol synthetic pathway from Clostridium acetobutylicum is represented with black arrows, for each strategy only the alternative catalytic steps/enzymes are shown. Alternatives described in the literature to this pathway including gene knockout and overexpression are highlighted in the respective color. Dashed lines represent successive enzymatic reactions and $X$ indicates gene knockouts. 2Hxg, 2-hydroxygulatarate; $2 \mathrm{HxgCoA}$, 2-hydroxyglutaryl-CoA; acacCoA, acetoacetyl-CoA; acCoA, acetyl-CoA; Acet, acetate; ACP, acyl-acyl carrier protein; ActP, acetyl-phosphate; AF, Acidaminococcus fermentans; BF, Bacteroides fragilis; BS, Bacillus subtilis; CA, Clostridium acetobutylicum; Cit, citrate; EC, Escherichia coli; EtOH, ethanol; Form, formate; Fum, fumarate; GlcnCA, glutaconyl-CoA; Ile, isoleucine; Isocit, isocitrate; Lact, lactate; Leu, leucine; LL, Lactococcus lactis; Mal, malate; Met, methionine; MM, Mycobacterium marinum; OAA, oxaloacetate; OXG, 2-oxoglutarate; PA, Pseudomonas aeruginosa; PEP, phosphoenolpyruvic acid; Pyr, pyruvate; RE, Ralstonia eutropha; SC, Saccharomyces cerevisiae; Succ, succinate; succCoA, succinyl-CoA; TD, Treponema denticola; Val, valine [Color figure can be viewed at wileyonlinelibrary.com]

clostridial pathway and the high demand for NADH and acetyl-CoA. Nevertheless, the cost, the inconsistency and consequent limited reproducibility of complex components hinder their application in large-scale, and for this reason some authors have explored more sustainable and renewable substrates (Hahn-Hägerdal et al., 2005; Masri, Garbe, Mehlmer, \& Brück, 2019).

The highest reported butanol titer $(30 \mathrm{~g} / \mathrm{L})$ was achieved by in situ gas striping of butanol and intermittent linear feeding of glucose (Shen et al., 2011). This approach to remove butanol led to twofold increment from 15 to $30 \mathrm{~g} / \mathrm{L}$. An economically viable fermentation should achieve a titer of $100 \mathrm{~g} / \mathrm{L}$ and its productivity should exceed $2 \mathrm{~g} \cdot \mathrm{L}^{-1} \cdot \mathrm{hr}^{-1}$ (Sheridan, 2009). To be able to achieve these industrial standards using E. coli as a butanol producer, some challenges must be addressed by applying rational design strategies, namely (a) conversion of sustainable substrates, (b) elimination of competing pathways, (c) cofactor balancing to increase NADH pool, (d) fine tuning of heterologous pathway expression,and (e) improvement of E. coli tolerance to butanol. These different strategies and the respective progress obtained so far are described in detail in the next sections.

\section{1 | Conversion of alternative substrates to develop a sustainable process}

The production of biofuels from cheap and renewable raw-materials can lead to more sustainable processes able to compete with the petrochemical industry. Some alternative substrates that have been used for butanol production include glycerol, cellulose, hemicellulose, switchgrass, and fatty acids (FA; Ndaba et al., 2015; Zheng et al., 2009). 


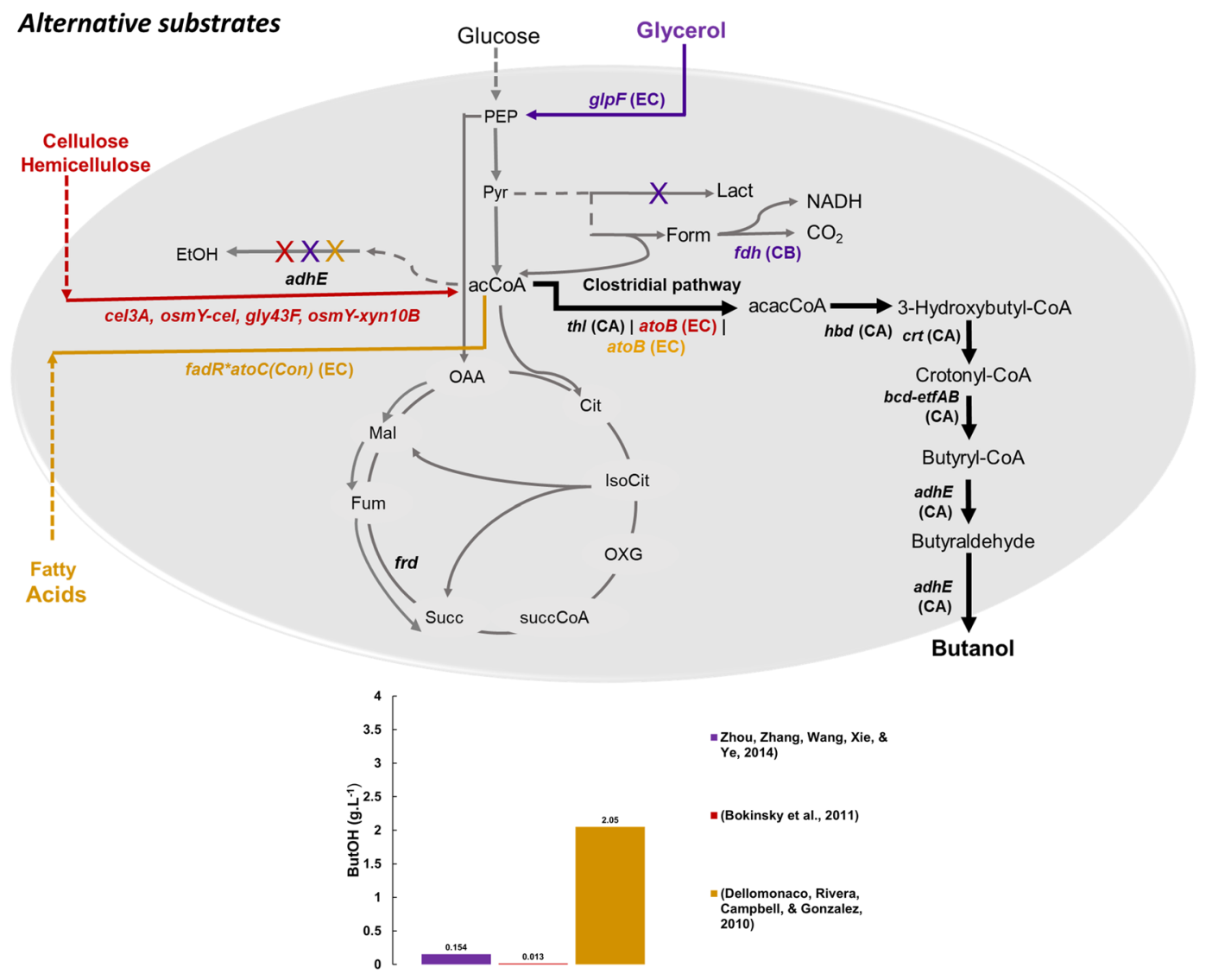

FIGURE 4 Schematic overview of the different strategies reported in the literature to produce butanol in Escherichia coli converting alternative substrates. Besides the alternative pathways to produce butanol, the genetic strategies to improve butanol production are also depicted. For each group of strategies tested in each reference, only the best butanol producing combination is shown. The $n$-butanol synthetic pathway from Clostridium acetobutylicum is represented with black arrows, for each strategy only the alternative catalytic steps/enzymes are shown. Alternatives described in the literature to this pathway including gene knockout and overexpression are highlighted in the respective color. Dashed lines represent successive enzymatic reactions. acacCoA, acetoacetyl-CoA; acCoA, Acetyl-CoA; CA, Clostridium acetobutylicum; $\mathrm{CB}$, Candida boidinii; Cit, citrate; EC, Escherichia coli; EtOH, ethanol; Form, formate; Fum, fumarate; Isocit, isocitrate; Lact, lactate; Mal, malate; OAA, oxaloacetate; OXG, 2-oxoglutarate; PEP, phosphoenolpyruvic acid; Pyr, pyruvate; Succ, succinate; succCoA, succinyl-CoA [Color figure can be viewed at wileyonlinelibrary.com]

Glycerol is an abundant by-product from biodiesel production, and it can enhance the synthesis of butanol since it is a more reduced substrate when compared with glucose. Zhou et al. explored the production of butanol from glycerol by overexpressing the transporter GlpF. This modification improved the consumption of glycerol into the cell by $25 \%$ and as a result the butanol titer also improved $23 \%$. In this study, after disrupting NADH-competing pathways, the highest butanol titer achieved was $0.154 \mathrm{~g} / \mathrm{L}$ (Zhou, Zhang, Wang, Xie, \& Ye, 2014).

Another possibility is consolidated bioprocessing, this approach combines biomass hydrolysis and fuel production, reducing the costs in the pretreatment of lignocellulosic biomass. This strategy has been explored for butanol production mostly with clostridial strains, as comprehensively reviewed by Taherzadeh group (Jouzani \& Taherzadeh, 2015). Regarding biobutanol production in E. coli, the Keasling group has developed a cellulolytic strain of E. coli capable of growing on switchgrass by secreting cellulases and hemicellulases. In this process, switchgrass was first pretreated with ionic liquids (ILs) to release cellulose and hemicellulose components. The strain containing the heterologous butanol pathway on a single plasmid was able to produce $0.028 \mathrm{~g} / \mathrm{L}$ butanol from defined rich medium containing $3.3 \% \mathrm{w} / \mathrm{v}$ IL-treated switchgrass as the main carbon source (Bokinsky et al., 2011).

The interest on using FA as substrate had emerged due to the availability of FA-rich feedstocks and its efficient metabolism which can support high product yields on substrate. Particularly, FA metabolism to acetyl-CoA results in full carbon recovery in contrast with sugar metabolism where formate or carbon dioxide are also formed. Nevertheless, the incorporation of the highly reduced FA generates an excess of reducing-equivalents, requiring the presence of an exogenous electron acceptor. So, the conversion of FA is only possible under aerobic conditions which hinders butanol production. The conversion of FA in E. coli is mediated by enzymes encoded by 


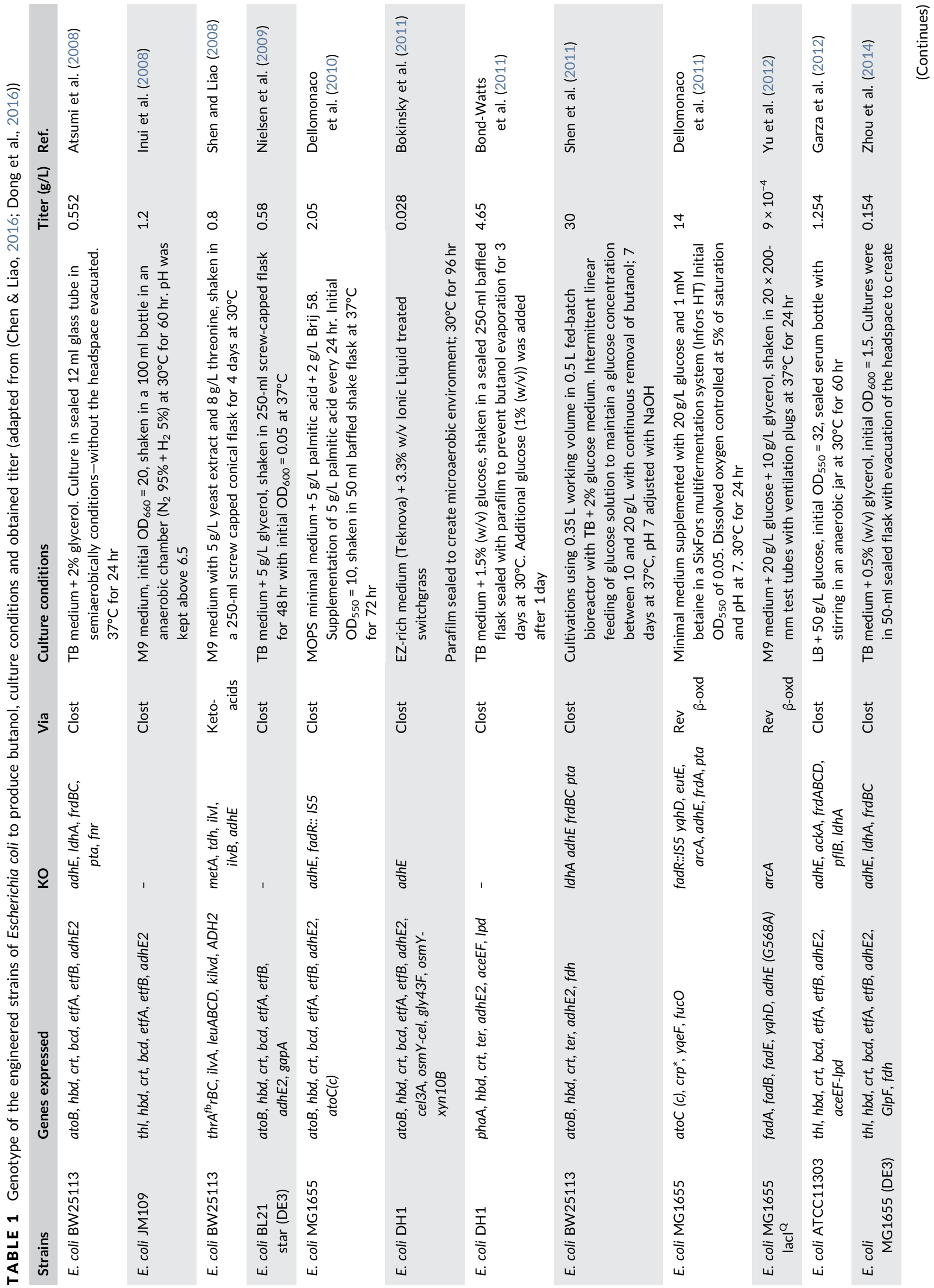




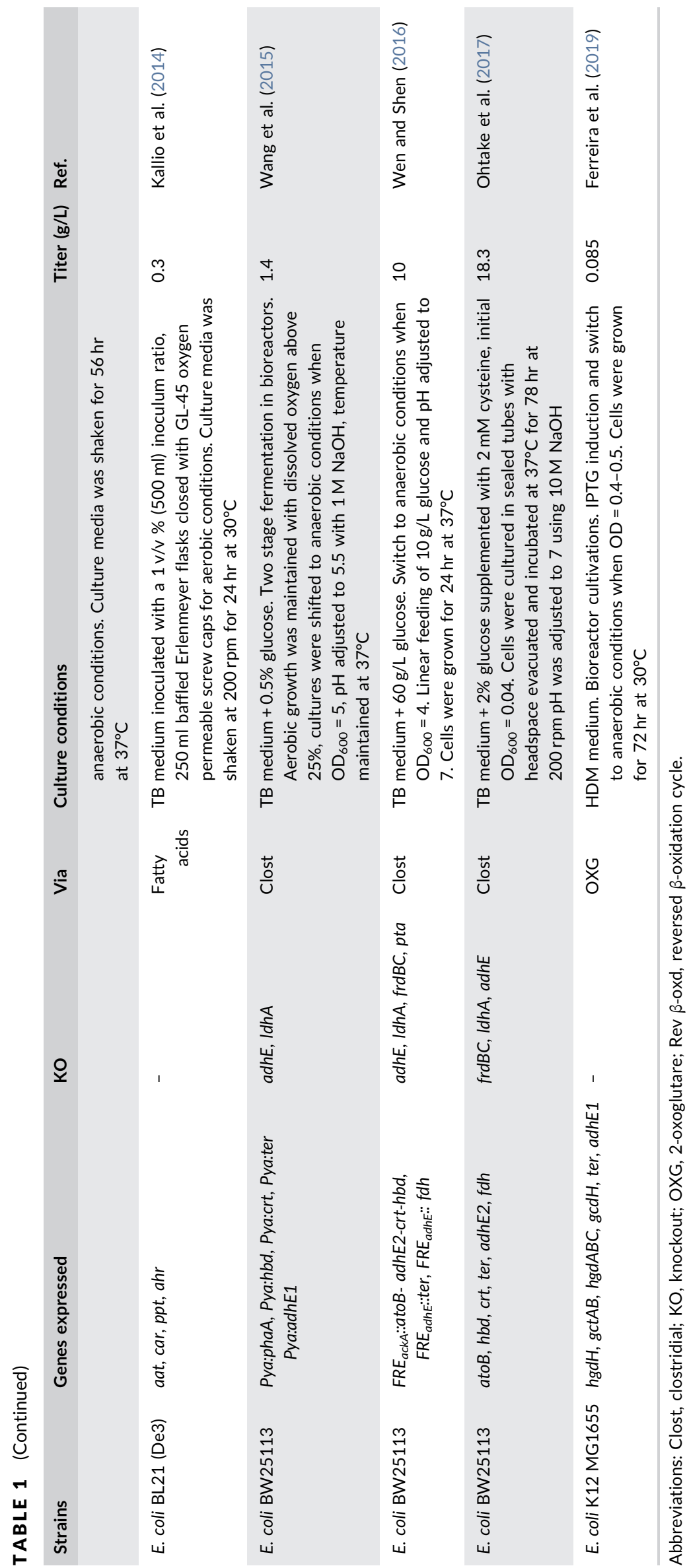


the fad regulon and the ato operon. By expressing these genes and engineering a respiro-fermentative metabolism, the Gonzalez group has developed strains of $E$. coli capable of converting FA into $2.05 \mathrm{~g} / \mathrm{L}$ of butanol (Dellomonaco, Rivera, Campbell, \& Gonzalez, 2010)

The most abundant carbon source in biomass hydrolysates is usually glucose, although xylose also represents a significant portion in these preparations. $E$. coli has a diauxic growth when cultivated in media with both sugars, consuming only alternative sugars after glucose depletion. The synchronized consumption of both hexose and pentose sugars could increase the substrate consumption rates. (Gonzalez, Long, \& Antoniewicz, 2017; Wang, Goh, \& Beller, 2018). Recently, the genome of $E$. coli was engineered to develop a strain that consumes simultaneously both glucose and xylose. This strategy was applied to the production of methyl ketones under anaerobic conditions, alleviating the carbon catabolite repression (Wang et al., 2018). The development of an efficient fermentation process to the production of butanol can benefit from the progress achieved so far in this field.

\section{2 | Elimination of competing pathways for butanol production to increase precursors and cofactor availability}

The internal metabolic fluxes in a microorganism evolved to fulfill its own requirements generating advantages in a given environment, which usually means that genetic interventions are required to change the fluxes to satisfy industrial goals (Burgard, Pharkya, \& Maranas, 2003; Maia, Rocha, \& Rocha, 2016). The elimination of competing pathways by gene disruption is a common strategy to enforce overproduction of a certain biochemical compound. In E. coli, this approach was effectively applied in the production of a wide variety of compounds such as succinate (Jantama et al., 2008), ethanol (Kim, Ingram, \& Shanmugam, 2007) and L-alanine (Zhang, Jantama, Moore, Shanmugam, \& Ingram, 2007).

Particularly, when producing butanol under anaerobic conditions, the common by-products of $E$. coli include ethanol, lactate and acetate, the so-called mixed-acid fermentation products. In conditions without oxygen available, the tricarboxylic acid (TCA) cycle is downregulated, so two NADH molecules per glucose catabolized need to be recycled to $\mathrm{NAD}^{+}$using mixed-acid fermentation pathways. Also, in anaerobiosis, E. coli metabolizes pyruvate using the pyruvate formate lyase ( $P F L$ ), which prevents the release of additional NADH, forming formate and acetyl-CoA instead. Acetyl-CoA can then be converted into acetate by the action of the enzymes encoded by ackA-pta, forming adenosine triphosphate (ATP) or into ethanol by action of adhE, recycling two molecules of NADH per ethanol produced. Lactate synthesis from pyruvate also allows recycling NADH (one per lactate). In addition to these three routes, E. coli can also produce succinate through the reductive branch of the TCA cycle, while recycling two molecules of NADH per succinate produced.
Acetate is usually an undesired by-product during $E$. coli fermentations because it decreases cellular growth and protein production even at concentrations as low as $0.5 \mathrm{~g} / \mathrm{L}$; thus the abolishment of acetate production is a subject of intensive research (Eiteman \& Altman, 2006). Specifically, when expressing the clostridial pathway, the main goal of disrupting the genes involved in the production of acetate is to increase the acetyl-CoA pool, the main precursor for butanol synthesis. This reason led to the inactivation of acetate production in several works (Ohtake, Pontrelli, Laviña, Liao, \& Putri, 2017; Shen et al., 2011). Shen et al. have observed that the deletion of pta in JCL166 strain ( $\triangle a d h E \Delta l d h A \Delta f r d)$ was crucial to increase the acetyl-CoA pool, resulting in a threefold higher butanol titer. Nonetheless, Liao's group have observed a negative impact on butanol's production after deleting pta. Only by coupling this knockout with the deletion of $\mathrm{fnr}$-and consequent enhancement on the expression level of the pyruvate dehydrogenase (PDH) complexthe authors have obtained a 3-fold higher titer of butanol (Atsumi et al., 2008).

Producing one molecule of butanol from acetyl-CoA requires four molecules of NADH when the clostridial pathway is used. So, the redistribution of the metabolic fluxes from the production of native fermentation products toward butanol production, usually involves the elimination of competing $\mathrm{NADH}$-recycling pathways such as ethanol $(a d h E)$, lactate $(I d h A)$, and succinate $(f r d)$, represented in Figures 2-4 and widely described in Table 1 . The disruption of adhE is the most common within the strategies represented in Figures 2-4. The elimination of adhE allows simultaneously to prevent acetyl-CoA pool from being drained and to stop the recycling of two molecules of $\mathrm{NADH}$ for ethanol production. It was also proven that the alcohol dehydrogenase from $C$. acetobutylicum is more efficient to produce butanol than the one from $E$. coli due to its higher affinity to butyrylCoA than to acetyl-CoA (Atsumi et al., 2008). Nevertheless, other enzymes with alcohol/aldehyde dehydrogenase activities such as $\mathrm{mhpF}$, adhP, and $y q h D$ can still lead to ethanol accumulation ( $\mathrm{Yu}$, Alexandra, Skorokhodova, \& Debabov, 2012). In the work developed by Atsumi et al. (2008), the disruption of several genes (adhE, IdhA, frdBC, fnr and pta) increased 2.6-fold butanol titer and reduced the accumulation of acetate, ethanol, and lactate. The Liao group developed the E. coli strain able to achieve the maximum butanol titer so far $(30 \mathrm{~g} / \mathrm{L})$ and observed a fourfold improvement on butanol accumulation after knocking-out the genes adhE, IdhA, frdBC, and pta (Shen et al., 2011). NADH recycling is necessary for cells to keep metabolizing glucose and growing in anaerobic conditions. Therefore, preventing $\mathrm{NADH}$ recycling in the mixed fermentation pathway makes growth dependent on the use of the butanol pathway as a sink for this cofactor.By coupling growth to the production of butanol, a driving force is created to promote product formation. In this study, the accumulation of NADH was established by first deleting the mixed acid fermentation reactions ( $\triangle a d h E \Delta l d h A \triangle f r d B C$ ). Also, the complex bcd-etfAB, which uses ferredoxin as reducing power, was replaced by the $\mathrm{NADH}$-dependent ter from Treponema denticola to increase the NADH requirement of the pathway (Shen et al., 2011). 
In three alternative pathways-keto-acids (Shen \& Liao, 2008), the reversal $\beta$-oxidation cycle pathways (Dellomonaco, Clomburg, Miller, \& Gonzalez, 2011; Yu et al., 2012) and the ACP-dependent FA pathway (Kallio, Akhtar, \& Jones, 2014)-other genes were disrupted, mostly to redirect the flux toward butanol. Particularly, the exploration of the keto-acids pathway by the Liao group included gene deletions to increase the main precursor (2-ketobutyrate) pool in butanol production. Specifically, the genes ilvB and ilvl were deleted leading to a twofold increase in the butanol titer (Shen \& Liao, 2008). Regarding the reversal $\beta$-oxidation cycle pathways, two different approaches were followed to achieve butanol production (Dellomonaco et al., 2011; Yu et al., 2012). In both works, the activation of the reversal $\beta$-oxidation cycle pathway in the absence of its natural substrate implied the inactivation of arcA since the protein product of this gene mediates the repression of most operons encoding the $\beta$-oxidation cycle. Moreover, in the work developed by the Gonzalez group, the mixed-acid fermentation pathways ( $a d h E$, pta, and frdAB) were also knocked-out (Dellomonaco et al., 2011).

\subsection{Cofactor balancing to increase NADH pool}

When developing an efficient cell factory for the production of highly reduced compounds (such as alcohols), the cofactor balance is one of the major aspects to be considered. Besides removing mixed-acid fermentation pathways as described in the previous section, other ME strategies can be applied to increase NADH pool. An easy way to increase the availability of NADH is by cultivating cells in low oxygen conditions. Without oxygen to act as an electron sink, the molecules of NADH formed in glycolysis must be recycled to $\mathrm{NAD}^{+}$by forming reduced compounds, such as alcohols. The NADH recycling mechanisms support the maintenance of the redox balance inside the cells, a mandatory requirement for living cells sustain their growth. Although under aerobic conditions the regeneration of NADH using oxidative phosphorylation generates ATP, in the absence of oxygen the NADH recycling will cause the accumulation of NADH consuming byproducts. So, to couple cell growth with butanol synthesis, cultivations are usually oxygen-limited (Trinh, Li, Blanch, \& Clark, 2011).

The glycolysis end-product, pyruvate, can follow different routes in anaerobic conditions to fulfill growth and cofactor balancing requirements. Pyruvate can be converted into acetyl-CoA by two enzymes: PFL and PDH complex. PFL is active under anaerobic conditions, catalyzing the conversion of pyruvate into acetyl-CoA and formate. On the other hand, the PDH complex releases $\mathrm{NADH}$ and $\mathrm{CO}_{2}$ instead of formate. So, if the PDH is artificially activated in anaerobic conditions by overexpressing the aceEF-Ipd operon, it can provide extra NADH, which increases the recycling requirements for this cofactor. This approach was successfully applied to the production of butanol, achieving a 1.6-fold improvement and a final titer of $4.65 \mathrm{~g} / \mathrm{L}$ (Bond-Watts, Bellerose, \& Chang, 2011). Another study only achieved a 1.1-fold increment on butanol production, but a two-times higher yield on the substrate (Garza et al., 2012). The PDH complex is constituted by three enzyme subunits: pyruvate decarboxylase (encoded by aceE), dihydrolipoamide acetyltransferase (aceF), and dihydrolipoamide dehydrogenase (encoded by $l p d$ ). This last enzyme is inhibited when exposed to high concentrations of NADH (de Graef, Alexeeva, Snoep, \& Teixeira de Mattos, 1999), which can explain the modest improvements on butanol observed when overexpressing PDH complex under anaerobic conditions (Y. Kim, Ingram, \& Shanmugam, 2008; Lim, Seo, Kim, \& Jung, 2013). Another strategy followed by the Liao group consisted in inactivating the regulator fnr (which represses the expression of the PDH complex under anaerobic conditions). Nevertheless, the sole deletion of fnr decreased butanol production. As mentioned in the previous section, only by coupling the previous strategy to the deletion of pta (involved in the production of acetate from acetyl-CoA), a threefold improvement on butanol production was obtained (Atsumi et al., 2008).

In $E$. coli, the native formate dehydrogenase catalyzes the conversion of formate into $\mathrm{CO}_{2}$ and $\mathrm{H}_{2}$. However, in other microorganisms, the same enzyme can hydrolyze formate into $\mathrm{CO}_{2}$ and $\mathrm{NADH}$. Shen and coworkers, to further increase the NADH pool, expressed the formate dehydrogenase from Candida boidinii, leading to a higher butanol titer when the medium was supplemented with formate (Shen et al., 2011). Nielsen et al. expressed fdh from S. cerevisiae, which resulted in an improvement of $74 \%$ on butanol concentration. The supplementation of formate led to even higher concentrations (Nielsen et al., 2009).

\subsection{Fine tuning of heterologous pathway expression to overcome enzymatic bottlenecks}

\section{Expression of nonclostridial enzymes}

The clostridial butanol biosynthetic pathway is constituted by six catalytic steps converting two molecules of acetyl-CoA into one of butanol. The seven genes (thl, hbd, crt, bcd-etfAB, adhE) constituting this pathway are sufficient to support butanol production in $E$. coli (Inui et al., 2008). Nonetheless, the determination of rate-limiting steps and the expression of alternative genes more suitable to the host can lead to a more efficient cell factory

\section{Thiolase}

The first step of the clostridial butanol biosynthetic pathway is the thermodynamically unfavorable $\left(\Delta_{\mathrm{r}} G^{\prime m}=26.1 \pm 1.7 \mathrm{~kJ} / \mathrm{mol}\right.$ and $K_{\text {eq }}^{\prime}=$ $2.6 \times 10^{-5}$ ) condensation of two molecules of acetyl-CoA into one of acetoacetyl-CoA by the action of a thiolase (encoded by thl). Although the thermodynamics of a reaction are not dependent on the enzyme used, the rate of a reaction can be improved by an increment in enzymatic activity. For this reason, enzyme homologs from nonclostridial sources have been tested to catalyze this step. E. coli expresses three enzymes with acetyl-CoA acetyltransferase activity: AtoB, FadA, and YqeF. AtoB has a higher specific activity when compared with clostridial thiolase Thl (AtoB, 1,078 U/mg against Thl, $216 \mathrm{U} / \mathrm{mg}$ ). As observed in Figures 2 and 4, in most of the butanol production studies in $E$. coli, the gene thl was replaced by atoB from 
E. coli. The overexpression of this native enzyme was tested in the first reported recombinant production of butanol in E. coli (Atsumi et al., 2008) resulting in a threefold improvement on butanol titer from 0.014 to $0.040 \mathrm{~g} / \mathrm{L}$. Nevertheless, in another study, the increment on butanol titer by replacing thl for $a t o B$ was not so significant: from 0.20 to $0.22 \mathrm{~g} / \mathrm{L}$ (Nielsen et al., 2009). This difference highlights that the activity of an enzyme is also dependent on other factors like the expression system or the host strain used. Another thiolase-the protein product of fadA-was tested in the work where the inverted $\beta$-oxidation cycle was explored for butanol production, achieving a modest butanol titer ( $<1 \mathrm{mg} / \mathrm{L}$; Yu et al., 2012). On the other hand, Dellomonaco et al. also took advantage of the native $\beta$-oxidation pathway to produce butanol in $E$. coli but overexpressing another thiolase (yqeF). The results were more promising in this case and the modified strains could achieve $2.2 \mathrm{~g} / \mathrm{L}$ of butanol in shake-flask and around $14 \mathrm{~g} / \mathrm{L}$ in bioreactor (Dellomonaco et al., 2011). Lastly, BondWatts and his coworkers, inspired in the recombinant production of polyhydroxyalkanoates in $E$. coli by transferring the respective pathway from Ralstonia eutrophus, have expressed part of this pathway in E. coli to produce butanol. The overexpression of the phaA gene showed the highest butanol accumulation $(4.65 \mathrm{~g} / \mathrm{L}$; Bond-Watts et al., 2011).

\section{3-Hydroxybutyryl-CoA dehydrogenase and 3-hydroxybutyryl-CoA dehydratase}

The protein products of the genes $\mathrm{hbd}$ and $\mathrm{crt}$ from $\mathrm{C}$. acetobutylicum are commonly used to catalyze the reduction of acetoacetyl-CoA into 3-hydroxybutylryl-CoA and subsequent dehydration in crotonyl-CoA (Dong et al., 2016). Nevertheless, the enzymes encoded by phaB and phaJ-part of PHB pathway from R. eutrophus-could be used to replace the clostridial genes hbd and crt, as long as they are used together due to the stereochemical difference between the $\mathrm{Crt}$ substrate ((S)-3-hydroxybutyryl-CoA) and the PhaB product $((R)$ 3-hydroxybutyryl-CoA) (Bond-Watts et al., 2011; Dong et al., 2016). In the work developed by Bond-Watts and coworkers, the strains expressing the clostridial genes $h b d$ and crt achieved slightly higher butanol titers than the ones expressing simultaneously phaB and phaJ. In the work exploring the inverted $\beta$-oxidation pathway developed by the Debabov group, a single enzyme was expressed to catalyze these two steps, the protein product of the gene fadB from E. coli (Yu et al., 2012). Although no comparative experiments were performed with clostridial enzymes, this combination of enzymes allowed accumulating $9 \times 10^{-4} \mathrm{~g} / \mathrm{L}$ of butanol.

\section{Butyryl-dehydrogenase}

The reduction of crotonyl-CoA into butyryl-CoA is catalyzed in the clostridial pathway by butyryl-CoA dehydrogenase (Bcd), which requires the presence of the electron-transferring flavoprotein complex (EtfAB). The expression of this enzyme in E. coli is challenging due to its oxygen sensitivity and the requirement of ferredoxin as the electron donor (Dong et al., 2016; Shen et al., 2011).

Therefore, alternative enzymes catalyzing this particular step were tested in some studies. For instance, the Liao group has replaced bcd-etfAB by ccr from Streptomyces coelicolor, but lower titers of butanol were achieved (Atsumi et al., 2008). In another study, the authors further explored the expression of $c c r$ as part of a synthetic butanol pathway, concluding that this enzyme favors ethylmalonylCoA formation (65\%) over butyryl-CoA (35\%), providing a route for carbon to exit the butanol pathway (Bond-Watts et al., 2011). In fact, the difficulty of functionally expressing bcd-etfAB complex in $E$. coli was only overcome by expressing another class of enzymes with the same activity: trans-enoyl-reductases. The reduction of crotonyl-CoA into butyryl-CoA mediated by ter is an irreversible reaction in contrast with the reversible reaction catalyzed by the flavin-dependent Bcd-EtfAB complex. The replacement of bcd-etfAB by ter effectively increased the productivity of $n$-butanol in E. coli from $0.15-0.2$ to $2.95 \mathrm{~g} / \mathrm{L}$ (Bond-Watts et al., 2011). Shen et al. have also tested the effect of expressing ter from different sources on butanol titer, namely from $T$. denticola, Treponema vincentii, Fibrobacter succinogenes, and Flavobacterium johnsoniae. Cells expressing ter from T. denticola achieved the highest butanol titer (Shen et al., 2011). They also subjected the three Ter homologs from $T$. vincentii, F. succinogenes, and $F$. johnsoniae to error-prone polymerase chain reaction (PCR) mutagenesis. By doing so, they were able to find mutants with enhanced activity comparing with the wild-type counterpart. The ter mutant (Met11Lys) from F. succinogenes was the one with the higher activity but was only able to reach a butanol titer similar to strains expressing ter from $T$. denticola.

\section{Aldehyde/alcohol dehydrogenase}

The two last steps of the clostridial pathway to produce butanol are the two successive reductions of butyryl-CoA into butyraldehyde and to butanol, recycling two molecules of $\mathrm{NADH}$. In clostridial strains, these two steps are catalyzed by the same enzyme, the bifunctional aldehyde/ alcohol dehydrogenase. Clostridial strains express two aldehyde/alcohol dehydrogenases, one during acidogenesis (adhE1) and the other in the solventogenic phase (adhE2) (Dong et al., 2016; Nielsen et al., 2009). Inui and coworkers have studied the effect of expressing these two enzymes on butanol accumulation in E. coli (Inui et al., 2008). They concluded that adhE2 has higher specificity toward butyryl-CoA than adhE1, resulting in around fourfold improvement on butanol production. In the work published by Nielsen et al. the higher specificity toward butyryl-CoA was not reflected on butanol accumulation, since similar butanol titers were obtained independently of the bifunctional enzyme expressed (Nielsen et al., 2009).

In a different approach, the Debabov group has expressed a single mutated alcohol dehydrogenase adhE568 to turn this enzyme active under semiaerobic conditions to explore the inverted $\beta$-oxidation pathway to produce butanol. To do so, a point mutation was introduced in adhE coding sequence, leading to a Glu568Lys substitution in the encoded enzyme. Nonetheless, the maximum butanol production was still $<1 \mathrm{mg} / \mathrm{L}$ (Yu et al., 2012).

Finally, in the work exploring a $\mathrm{O}_{2}$-tolerant pathway, this last step was catalyzed by aldehyde reductases selected based on their broad substrate specificity (Kallio et al., 2014). The authors have tested the endogenous enzyme or the overexpression of two 
enzymes: slr1192 from Synechocystis sp. PCC 6803 and ahr from E. coli. The maximum butanol, titer $(0.3 \mathrm{~g} / \mathrm{L})$ was obtained by overexpressing the protein encoded by the gene $a h r$.

\section{Optimization of expression of pathway genes}

The maximization of the carbon flux in a pathway implies the fine-tuning of the heterologous gene expression. To do so, several techniques are available such as codon-optimization, modulation of ribosome binding sites (RBS); manipulation of messenger RNA (mRNA) stability; engineering promoter strengths, or modification of gene copy number (Zhao, Zhao, Li, \& Zhang, 2017). Some of these techniques were applied for butanol production in E. coli as described in more detail bellow.

Particularly, the modification of the RBS of a mRNA transcript controls the translation efficiency, allowing to regulate enzyme production at the RNA level (Copeland et al., 2013). Ohtake et al. (2017) designed different RBS to control adhE2 expression and achieve an optimal translation rate. In this study, a library of eight clones was generated using RBS calculator (Salis, 2011), optimizing the production of butanol and lowering by-product formation. The highest $n$-butanol producer with a modified RBS region was able to accumulate more than $7 \mathrm{~g} / \mathrm{L}$ compared with $3.9 \mathrm{~g} / \mathrm{L}$ by the original RBS region.

Another approach that was proven to be efficient was the expression of butanol production genes under the control of native fermentation regulatory elements (FRE) of the major fermentative genes (Wen \& Shen, 2016). This allowed constructing a self-regulated butanol production system in E. coli, a strain able to auto-induce butanol production under anaerobic conditions in the absence of IPTG and antibiotics. In this study, different FRE were combined with the butanol producing genes resulting in several FRE::gene constructions. The best strain was able to excrete $10 \mathrm{~g} / \mathrm{L}$ of butanol under anaerobic conditions. Wang and coworkers have integrated the butanol production genes into $E$. coli genome under the control of the native anaerobic promoter $P_{\text {hya }}$ achieving $1.4 \mathrm{~g} / \mathrm{L}$ of butanol (Wang et al., 2015).

\section{Implementation of novel pathways}

Some of the challenges mentioned above could be tackled by implementing in E. coli novel pathways to produce butanol more suitable to the host metabolism. Most of the studies reported so far have focused on engineering the clostridial pathway, as depicted in Figures 2 and 4 and described in Table 1. Until now, only five significantly different alternative pathways for producing butanol have been tested in E. coli (Figure 3). One explores the keto-acids metabolism (Shen \& Liao, 2008), an $\mathrm{O}_{2}$-tolerant pathway based on the activities of an ACP-thioesterase and a promiscuous carboxylic acid reductase (Kallio et al., 2014), a pathway using 2-oxoglutarate as precursor (Ferreira, Pereira, Liu, Vilaça, \& Rocha, 2019) and the remaining two explore an engineered version of the $\beta$-oxidation pathway present in E. coli (Dellomonaco et al., 2011; Yu et al., 2012). For each alternative pathway, the obtained progress and the respective challenges are described in more detail bellow.

The first alternative pathway to produce butanol in E. coli was developed by Shen et al. in 2008 , where a strain of E. coli was designed to simultaneously produce butanol and propanol by exploiting the keto-acid pathway (Shen \& Liao, 2008). In this study, E. coli was engineered to increase the pool of 2-ketobutyrate, a common ketoacid intermediate in isoleucine biosynthesis. This keto-acid can then be converted into 1-propanol, by the action of heterologous decarboxylases and dehydrogenases, or into butanol through the norvaline biosynthetic pathway. In this study, the authors took advantage of the native amino acid pathway overcoming the need to involve CoA-dependent intermediates. The engineered strain was able to accumulate $0.8 \mathrm{~g} / \mathrm{L}$ of butanol.

An approach to engineer the reverse $\beta$-oxidation cycle native from $E$. coli has also been demonstrated to allow $n$-butanol production (Dellomonaco et al., 2011). Dellomonaco et al. engineered $E$. coli to activate this pathway in the absence of the inducing substrate (FA). The constitutive expression of this pathway without the respective substrate was achieved by introducing mutations in the corresponding transcriptional regulators ( $\mathrm{fad}$, ato, and $\mathrm{crp}$ ) and knocking-out $\operatorname{arcA}$. Further disruption of fermentation pathways ( $\triangle a d h E, \Delta \operatorname{rdA}, \Delta p t a)$ and overexpression of native thiolase (YqeF) and alcohol dehydrogenase (FucO) led to a production of $n$-butanol of $2.2 \mathrm{~g} / \mathrm{L}$ in shake-flask and $14 \mathrm{~g} / \mathrm{L}$ in bioreactor. In a similar approach, the Debabov group also explored the reversed $\beta$-oxidation pathway, but only expressing enzymes from this pathway and an aerotolerant mutant adhE to convert butyryl-CoA into butanol. In this study, no competing pathways were eliminated and the maximum butanol titer achieved was quite low ( $<1 \mathrm{mg} / \mathrm{L})$ when compared with other studies (Yu et al., 2012).

Kallio et. al have established an alternative to the CoAdependent pathway: an $\mathrm{O}_{2}$-tolerant via to produce butanol taking advantage of the native FA biosynthesis pathway (Kallio et al., 2014). In this study, an Acyl-ACP thioesterase with a specificity for butyrylACP and an oxygen-insensitive carboxylic acid reductase were expressed. The authors also observed that butanol titer increased by overexpressing a native aldehyde reductase. The greatest butanol titer obtained was $0.3 \mathrm{~g} / \mathrm{L}$.

Lastly, our group has explored the results generated by a hyper-graph algorithm implementing a novel pathway with 2-oxoglutarate as the precursor. In this pathway, the first reactions are part of the glutamate fermentation pathway from the microorganism Acidaminococcus fermentans and the last steps are common to the clostridial pathway. The highest titer achieved was $0.085 \mathrm{~g} / \mathrm{L}$ (Ferreira et al., 2019). This study validates in vivo the application of computational methods that reconstruct uncommon pathways from databases of enzymatic reactions to expand the portfolio of butanol production routes (Liu, Vilaça, Rocha, \& Rocha, 2015; Ranganathan \& Maranas, 2010). So, the increasing number of metabolic reactions compiled in databases can broad even more 
the spectrum of possibilities for the prospection of new pathways. The application of computational tools for designing and reconstructing metabolic pathways was comprehensively reviewed by the Maranas group (Wang, Dash, Ng, \& Maranas, 2017) and by Kim et al. (2017).

\subsection{Improvement of E. coli tolerance to butanol}

One of the major problems when implementing an efficient bioprocess is to mitigate the toxicity effects on the host strains. In particular, $1 \%(\mathrm{v} / \mathrm{v})$ butanol is enough to inhibit the cellular growth by penetrating and accumulating in the membrane and the cytoplasm. This limitation hinders the development of an efficient bioprocess where titers of $100 \mathrm{~g} / \mathrm{L}$ are required.

Several strategies have been followed to improve butanol's tolerance in E. coli. One approach is to enhance the fluidity and integrity of the membrane by overexpressing heat-shock proteins (also known as chaperones). Chaperones act in response to stress conditions by folding and transporting proteins and disaggregating denatured proteins. $\mathrm{Xu}$ et al. have evaluated 30 alternative chaperones from different microorganisms in E. coli and cells expressing SecB achieved the highest tolerance to butanol. Furthermore, the authors created a random mutagenesis library of $\mathrm{SecB}$ using error-prone $\mathrm{PCR}$, and the tolerance to butanol was enhanced from $1.4 \%(\mathrm{v} / \mathrm{v})$ to $1.6-1.8 \%(\mathrm{Xu}$, Wu, Xiao, Han, \& Ni, 2019).

Another method to improve butanol tolerance consisted in exploring membrane transporters to pump out the solvent from the cells. These efflux pumps can simultaneously reduce the toxic effects, increase the productivity and facilitate the product recovery. Keasling group was able to increase butanol's tolerance of $E$. coli up to $1.9 \%$ by expressing $\operatorname{Ttg} A B C$, an efflux pump from $P$. putida with affinity to short-chain alcohols (Basler, Thompson, Ercek, \& Keasling, 2018). In this regard, the knockout of regulation genes can also improve the expression-levels of membrane transporters. For instance, the disruption of lon gene has increased the expression level of AcrAB-TolC efflux pump and consequently the butanol tolerance of E. coli (Watanabe, Doukyu, \& Bw, 2014).

Metallothioneins (MTs) can attenuate the oxidative stress in microorganisms by scavenging intracellular or extracellular reactive oxygen species. Chin et al. tested MTs from human, mouse and tilapia fish on their ability to reduce the oxidative stress induced by butanol. Cells expressing MT from tilapia fish had the best performance on tolerating butanol. The authors have also concluded that membrane damage could be decreased by expressing membrane-targeted MTs. Particularly, the TMT-fused OmpC protein could tolerate concentrations of butanol up to 1.5\% (Chin, Lin, Chang, \& Huang, 2013).

Finally, adaptive laboratory evolution (ALE) can help improve the tolerance of microbes to butanol. ALE is a powerful technique in which a microorganism is cultivated continuously for several generations, improving its fitness in a response to a certain condition (selective pressure) by natural selection (Horinouchi, Maeda, \& Furusawa, 2018). The subsequent whole-genome sequencing of the adapted strains can identify the mutations associated with butanol's tolerance. Further integration of "omics" technology can help to unravel the regulatory and metabolic mechanisms associated with butanol tolerance (Horinouchi et al., 2018). Jeong et al. (2017) have evolved a E. coli strain able to tolerate 1.3\% (v/v) butanol. By comparing the transcriptome and the phenome of the parental strain with the evolved one, the authors concluded that cis-regulatory mutations in six genes ( $a d h E$, groL, waaG, yabl, yfiF, and yqjA) were the cause of butanol tolerance.

\section{5 | FUTURE PERSPECTIVES}

As discussed in this review the production of butanol in its native host (Clostridium) and in E. coli still has a long way to go to compete with chemical synthesis processes. Further optimization of the host metabolic pathways using ME strategies will be necessary to reach industrially relevant titers and productivity. Furthermore, ALE can increase the tolerance to butanol by cultivating the cells for many generations in sequentially higher concentrations of the solvent. ALE can be combined with other techniques that increase genetic diversity to achieve tolerance phenotypes quicker. To do so, several tools are available including error-prone PCR, chemical or physical mutagenesis, multiplex automated genome engineering and RNAiassisted genome evolution (Chae, Choi, Kim, \& Ko, 2017; Long, Gonzalez, Feist, Palsson, \& Antoniewicz, 2018).

To date, many of the engineering efforts to improve butanol production have resulted in reduced growth and other unintended effects. By applying a systems biology approach to the problem, a better understanding of the cell physiology could further help integrating butanol production in a new host. For instance, by using different sets of "omics" data (e.g., transcriptomics and proteomics) it is possible to have the full picture of the metabolism, helping to identify possible ME strategies to increase the production of the target compounds (Zhang, Li, \& Nie, 2010). Using the information about the genes present in a certain organism, it is possible to know the enzymes expressed and respective catalyzed reactions. The collection of reactions present in an organism can be combined with knowledge of cellular metabolism (e.g., biomass composition and energy requirements), which can then be mathematically represented in genome-scale metabolic models. These models, when combined with constraint-based modeling methods, can predict phenotypes and further support rational ME-driven strategies. (Baumler, Peplinski, Reed, Glasner, \& Perna, 2011; Conrad, Lewis, \& Palsson, 2011; Feist, Herrgård, Thiele, Reed, \& Palsson, 2009; Maia et al., 2016).

As discussed in this review (see Section 4.4.3), generating new pathways can help bypass some of the problems affecting the clostridium butanol production pathway when expressed in E. coli. For this purpose, retrosynthesis algorithms allow to discover novel and/ or more efficient pathways taking as input a set of target metabolites. Examples of workflows based on this type of algorithms include BNICE (Wu, Wang, Assary, Broadbelt, \& Krilov, 2011) and RetroPath 
(Delépine, Duigou, Carbonell, \& Faulon, 2018). Another possibility is to apply computational protein design tools to either design de novo enzymes or to engineer existing proteins to have higher catalytic activity and substrate specificity, more stability and thermal tolerance (Chae, Choi, Kim, Ko, \& Lee, 2017).

Synthetic biology offers several techniques that can be used to implement and optimize microbial cell factories as described in Section 4.4.2. Particularly, the large number of heterologous genes expressed to produce butanol can result in a metabolic burden to the host cell imposed by IPTG induction and the high concentrations of plasmid replication. These effects can be alleviated by controlling gene expression through modulation of its components-promoter, ribosome RBS, terminator, untranslated region, and transcription factor-or with regulatory RNAs. Also, the CRISPR-Cas9 system allows to simultaneously manipulate multiple targets, broadening the spectrum of targets. Finally, the spatial modulation of enzymes is a strategy to decrease the probability of side reactions and attenuate the effects of unstable or toxic intermediates by locating closely the enzymes of the pathway (Chae et al., 2017; Choi et al., 2019).

Given the limited success in producing butanol in industrially relevant amounts, significant progress remains to obtain an efficient cell factory for this compound. By tackling the problems still affecting butanol production with the approaches discussed here, it is expected further gains that get this bioprocess closer to a competitive level.

\section{6 | CONCLUSIONS}

In this review, the different approaches reported to produce butanol in E. coli were gathered and the obtained progress was analyzed (Figures 2-4 and Table 1). Most of the ME strategies have been applied to increase the NADH pool available either by increasing its accumulation or by disrupting competing pathways. From the first published recombinant production of butanol in E. coli, butanol titer has increased more than 50 -fold, from 0.552 to $30 \mathrm{~g} / \mathrm{L}$, the maximum value obtained so far. The values obtained already can compete and even exceed clostridial titers, confirming the potential of using $E$. coli as a butanol cell factory. However, in most of the works gathered in this review, the yields on substrate are not shown. The presence of complex nutrients in the culture media can provide alternative carbon sources hindering the exact estimation of yields on substrate. So, it would be interesting to analyze the yield and productivity values to fully comprehend how effective the different strategies are.

Although promising, the values achieved so far are still distant from the ones required to implement a sustainable industrial process. Most of the reported studies were focused on answering a specific challenge like butanol toxicity, cofactor balancing, implementation of alternative pathways/enzymes and conversion of more sustainable substrates. The lack of a systematic and comprehensive analysis of the achieved efforts hinders the development of a fully efficient microbial cell factory. A wide range of $\mathrm{ME}$ tools can be combined in a synergistic way to tackle the remaining challenges and finally fill the gap between the currently obtained titers and the required industrial standards.

\section{ACKNOWLEDGMENTS}

This study was supported by the Portuguese Foundation for Science and Technology (FCT) under the scope of under the scope of a Ph.D. grant (PD/BD/52366/2013) from MIT Portugal Program, by the project "Dynamics," Ref. ERA-IB-2/0002/2014, funded by national funds through FCT/MCTES, by the strategic funding of UID/BIO/ 04469 unit and COMPETE 2020 (POCl-01-0145-FEDER-006684) and BioTecNorte operation (NORTE-01-0145-FEDER-000004) funded by the European Regional Development Fund under the scope of Norte2020-Programa Operacional Regional do Norte. The authors thank the project DDDeCaF-Bioinformatics Services for DataDriven Design of Cell Factories and Communities, Ref. H2020-LEITBIO-2015-1 686070-1, funded by the European Commission and the Project LISBOA010145FEDER007660 (Microbiologia Molecular, Estrutural e Celular) funded by FEDER funds through COMPETE2020 Programa Operacional Competitividade e Internacionalização ( $\mathrm{POCI}$ ) and by national funds through FCT Fundação para a Ciência e a Tecnologia. This study was funded by Project LISBOA010145FEDER007660 (Microbiologia Molecular, Estrutural e Celular) funded by FEDER funds through COMPETE2020 Programa Operacional Competitividade e Internacionalização $(\mathrm{POCl})$ and by national funds through FCT Fundação para a Ciência e a Tecnologia.

\section{CONFLICT OF INTERESTS}

The authors declare that there are no conflict of interests.

\section{ORCID}

Isabel Rocha (iD http://orcid.org/0000-0001-9494-3410

\section{REFERENCES}

Atsumi, S., Cann, A. F., Connor, M. R., Shen, C. R., Smith, K. M., Brynildsen, M. P., \& Liao, J. C. (2008). Metabolic engineering of Escherichia coli for 1-butanol production. Metabolic Engineering, 10(6), 305-311. https://doi.org/10.1016/j.ymben.2007.08.003

Basler, G., Thompson, M., Ercek, D. T., \& Keasling, J. (2018). A Pseudomonas putida efflux pump acts on short-chain alcohols. Biotechnology for Biofuels, 11, 136. https://doi.org/10.1186/s13068018-1133-9

Baumler, D. J., Peplinski, R. G., Reed, J. L., Glasner, J. D., \& Perna, N. T. (2011). The evolution of metabolic networks of E. coli. BMC Systems Biology, 5(1), 182. https://doi.org/10.1186/1752-0509-5-182

Blombach, B., \& Eikmanns, B. J. (2011). Current knowledge on isobutanol production with Escherichia coli, Bacillus subtilis and Corynebacterium glutamicum. Bioengineered Bugs, 2(6), 346-350. https://doi.org/10. 4161/bbug.2.6.17845

Bokinsky, G., Peralta-yahya, P. P., George, A., Holmes, B. M., Steen, E. J., \& Dietrich, J. (2011). Synthesis of three advanced biofuels from ionic liquid-pretreated switchgrass using engineered Escherichia coli. Proceedings of the National Academy of Sciences of the United States of America, 108(50), 19949-19954. https://doi.org/10.1073/pnas. 1106958108

Bond-Watts, B. B., Bellerose, R. J., \& Chang, M. C. Y. Y. (2011). Enzyme mechanism as a kinetic control element for designing synthetic biofuel 
pathways. Nature Chemical Biology, 7, 222-227. https://doi.org/10. 1038/nchembio.537

Buehler, E. A., \& Mesbah, A. (2016). Kinetic study of acetone-butanolethanol fermentation in continuous culture. PLOS One, 11(8), 1-21. https://doi.org/10.1371/journal.pone.0158243

Burgard, A. P., Pharkya, P., \& Maranas, C. D. (2003). OptKnock: A bilevel programming framework for identifying gene knockout strategies for microbial strain optimization. Biotechnology and Bioengineering, 84(6), 647-657. https://doi.org/10.1002/bit.10803

Chae, T. U., Choi, S. Y., Kim, J. W., \& Ko, Y. (2017). Recent advances in systems metabolic engineering tools and strategies. Current Opinion in Biotechnology, 47, 67-82. https://doi.org/10.1016/j.copbio.2017.06.007

Chae, T. U., Choi, S. Y., Kim, J. W., Ko, Y.-S., \& Lee, S. Y. (2017). Recent advances in systems metabolic engineering tools and strategies. Current Opinion in Biotechnology, 47, 67-82. https://doi.org/10.1016/j. copbio.2017.06.007

Chen, C. T., \& Liao, J. C. (2016). Frontiers in microbial 1-butanol and isobutanol production. FEMS Microbiology Letters, 363(5), 1-13. https://doi.org/10.1093/femsle/fnw020

Chin, W.-C., Lin, K.-H., Chang, J.-J., \& Huang, C.-C. (2013). Improvement of $\mathrm{n}$-butanol tolerance in Escherichia coli by membrane-targeted tilapia metallothionein. Biotechnology for Biofuels, 6(1), 130. https://doi.org/ 10.1186/1754-6834-6-130

Choi, K. R., Jang, W. D., Yang, D., Cho, J. S., Park, D., \& Lee, S. Y. (2019). Systems metabolic engineering strategies: Integrating systems and synthetic biology with metabolic engineering. Trends in Biotechnology, 37(8), 817-837. https://doi.org/10.1016/j.tibtech. 2019.01.003

Clomburg, J. M., \& Gonzalez, R. (2010). Biofuel production in Escherichia coli: The role of metabolic engineering and synthetic biology. Applied Microbiology and Biotechnology, 86(2), 419-434. https://doi.org/10. 1007/s00253-010-2446-1

Conrad, T. M., Lewis, N. E., \& Palsson, B. Ø. (2011). Microbial laboratory evolution in the era of genome-scale science. Molecular Systems Biology, 7(509), 509. https://doi.org/10.1038/msb.2011.42

Copeland, W. B., Bartley, B. A., Chandran, D., Galdzicki, M., Kyung, H., Sleight, S. C., \& Sauro, H. M. (2013). Computational tools for metabolic engineering. Metabolic Engineering, 14(3), 270-280. https://doi.org/10. 1016/j.ymben.2012.03.001

Delépine, B., Duigou, T., Carbonell, P., \& Faulon, J. (2018). RetroPath2. 0: A retrosynthesis work fl ow for metabolic engineers. Metabolic Engineering, 45, 158-170. https://doi.org/10.1016/j.ymben.2017.12.002

Dellomonaco, C., Clomburg, J. M., Miller, E. N., \& Gonzalez, R. (2011). Engineered reversal of the $\beta$-oxidation cycle for the synthesis of fuels and chemicals. Nature, 476(7360), 355-359. https://doi.org/10.1038/ nature10333

Dellomonaco, C., Rivera, C., Campbell, P., \& Gonzalez, R. (2010). Engineered respiro-fermentative metabolism for the production of biofuels and biochemicals from fatty acid-rich feedstocks. Applied and Environmental Microbiology, 76(15), 5067-5078. https://doi.org/10. 1128/AEM.00046-10

Dong, H., Zhao, C., Zhang, T., Lin, Z., Li, Y., \& Zhang, Y. (2016). Engineering Escherichia coli cell factories for $\mathrm{n}$-butanol production. In Q. Ye, J. Bao \& J.-J. Zhong (Eds.), Bioreactor engineering research and industrial applications I: Cell factories (pp. 141-163). Berlin, Heidelberg: Springer Berlin Heidelberg. https://doi.org/10.1007/10_2015_306

Dürre, P. (2007). Biobutanol: An attractive biofuel. Biotechnology Journal, 2(12), 1525-1534. https://doi.org/10.1002/biot.200700168

Dürre, P. (2008). Fermentative butanol production: Bulk chemical and biofuel. Annals of the New York Academy of Sciences, 1125, 353-362. https://doi.org/10.1196/annals.1419.009

Eiteman, M. A., \& Altman, E. (2006). Overcoming acetate in Escherichia coli recombinant protein fermentations. Trends in Biotechnology, 24(11), 530-536. https://doi.org/10.1016/j.tibtech.2006.09.001
Feist, A. M., Herrgård, M. J., Thiele, I., Reed, J. L., \& Palsson, B. (2009). Reconstruction of biochemical networks in microorganisms. Nature Reviews Microbiology, 7(2), 129-143. https://doi.org/10. 1038/nrmicro1949

Ferreira, S., Pereira, R., Liu, F., Vilaça, P., \& Rocha, I. (2019). Discovery and implementation of a novel pathway for n-butanol production via 2-oxoglutarate. Biotechnology for Biofuels, 12, 1-14. https://doi.org/10. 1186/s13068-019-1565-x

García, V., Päkkilä, J., Ojamo, H., Muurinen, E., \& Keiski, R. L. (2011). Challenges in biobutanol production: How to improve the efficiency? Renewable and Sustainable Energy Reviews, 15(2), 964-980. https://doi. org/10.1016/j.rser.2010.11.008

Garza, E., Zhao, J., Wang, Y., Wang, J., Iverson, A., Manow, R., \& Zhou, S. (2012). Engineering a homobutanol fermentation pathway in Escherichia coli EG03. Journal of Industrial Microbiology and Biotechnology, 39(8), 1101-1107. https://doi.org/10.1007/s10295-012-1151-8

Gonzalez, J. E., Long, C. P., \& Antoniewicz, M. R. (2017). Comprehensive analysis of glucose and xylose metabolism in Escherichia coli under aerobic and anaerobic conditions by $13 \mathrm{C}$ metabolic flux analysis. Metabolic Engineering, 39, 9-18. https://doi.org/10.1016/j.ymben.2016.11.003

de Graef, M. R., Alexeeva, S., Snoep, J. L., \& Teixeira de Mattos, M. J. (1999). The steady-state internal redox state (NADH/NAD) reflects the external redox state and is correlated with catabolic adaptation in Escherichia coli. Journal of Bacteriology, 181(8), 2351-2357.

Green, E. M. (2011). Fermentative production of butanol-The industrial perspective. Current Opinion in Biotechnology, 22(3), 337-343. https:// doi.org/10.1016/j.copbio.2011.02.004

Hahn-Hägerdal, B., Karhumaa, K., Larsson, C. U., Gorwa-Grauslund, M., Görgens, J., \& van Zyl, W. H. (2005). Role of cultivation media in the development of yeast strains for large scale industrial use. Microbial Cell Factories, 4(1), 31. https://doi.org/10.1186/1475-2859-4-31

Horinouchi, T., Maeda, T., \& Furusawa, C. (2018). Understanding and engineering alcohol-tolerant bacteria using OMICS technology. World Journal of Microbiology and Biotechnology, 34(11), 1-9. https://doi.org/ 10.1007/s11274-018-2542-4

Inui, M., Suda, M., Kimura, S., Yasuda, K., Suzuki, H., Toda, H., \& Yukawa, H. (2008). Expression of Clostridium acetobutylicum butanol synthetic genes in Escherichia coli. Applied Microbiology and Biotechnology, 77(6), 1305-1316. https://doi.org/10.1007/s00253-007-1257-5

Jang, Y. S., Malaviya, A., Cho, C., Lee, J., \& Lee, S. Y. (2012). Butanol production from renewable biomass by clostridia. Bioresource Technology, 123, 653-663. https://doi.org/10.1016/j.biortech.2012.07.104

Jantama, K., Zhang, X., Moore, J. C., Shanmugam, K. T., Svoronos, S. A., \& Ingram, L. O. (2008). Eliminating side products and increasing succinate yields in engineered strains of Escherichia coli C. Biotechnology and Bioengineering, 101(5), 881-893. https://doi.org/10.1002/bit.22005

Jeong, H., Lee, S. W., Kim, S. H., Kim, E. Y., Kim, S., \& Yoon, S. (2017). Global functional analysis of butanol-sensitive Escherichia coli and Its evolved butanol-tolerant strain. Journal of Microbiology and Biotechnology, 27(6), 1171-1179. https://doi.org/10.4014/jmb.1702.02021

Joseph, R. C., Kim, N. M., \& Sandoval, N. R. (2018). Recent developments of the synthetic biology toolkit for Clostridium. Frontiers in Microbiology, 9, 1-13. https://doi.org/10.3389/fmicb.2018.00154

Jouzani, G. S., \& Taherzadeh, M. J. (2015). Advances in consolidated bioprocessing systems for bioethanol and butanol production from biomass: A comprehensive review. Biofuel Research Journal, 5, 152-195. https://doi.org/10.18331/BRJ2015.2.1.4

Kallio, P., Akhtar, M. K., \& Jones, P. R. (2014). A synthetic O2-tolerant butanol pathway exploiting native fatty acid biosynthesis in Escherichia coli. Biotechnology and Bioengineering, 112(1), 120-128. https://doi.org/10.1002/bit.25324

Kim, S. M., Peña, M. I., Moll, M., Bennett, G. N., \& Kavraki, L. E. (2017). A review of parameters and heuristics for guiding metabolic pathfinding. Journal of Cheminformatics, 9(1), 1-13. https://doi.org/10.1186/s13321-017-0239-6 
Kim, Y., Ingram, L. O., \& Shanmugam, K. T. (2007). Construction of an Escherichia coli K-12 mutant for homoethanologenic fermentation of glucose or xylose without foreign genes. Applied and Environmental Microbiology, 73(6), 1766-1771. https://doi.org/10.1128/AEM.02456-06

Kim, Y., Ingram, L. O., \& Shanmugam, K. T. (2008). Dihydrolipoamide dehydrogenase mutation alters the nadh sensitivity of pyruvate dehydrogenase complex of Escherichia coli K-12. Journal of Bacteriology, 190(11), 3851-3858. https://doi.org/10.1128/JB.00104-08

Koppolu, V., \& Vasigala, V. K. (2016). Role of Escherichia coli in biofuel production. Microbiology Insights, 9, 29-35. https://doi.org/10.4137/ MBI.S10878

Lan, E. I., \& Liao, J. C. (2012). ATP drives direct photosynthetic production of 1-butanol in cyanobacteria. Proceedings of the National Academy of Sciences of the United States of America, 109(16), 6018-6023. https:// doi.org/10.1073/pnas.1200074109

Lee, K. H., Park, J. H., Kim, T. Y., Kim, H. U., \& Lee, S. Y. (2007). Systems metabolic engineering of Escherichia coli for L-threonine production. Molecular Systems Biology, 3, 149. https://doi.org/10.1038/msb4100196

Lim, J. H., Seo, S. W., Kim, S. Y., \& Jung, G. Y. (2013). Model-driven rebalancing of the intracellular redox state for optimization of a heterologous n-butanol pathway in Escherichia coli. Metabolic Engineering, 20, 56-62. https://doi.org/10.1016/j.ymben.2013.09.003

Liu, F., Vilaça, P., Rocha, I., \& Rocha, M. (2015). Development and application of efficient pathway enumeration algorithms for metabolic engineering applications. Computer Methods and Programs in Biomedicine, 118(2), 134-146. https://doi.org/10.1016/j.cmpb.2014.11.010

Long, C. P., Gonzalez, J. E., Feist, A. M., Palsson, B. O., \& Antoniewicz, M. R. (2018). Dissecting the genetic and metabolic mechanisms of adaptation to the knockout of a major metabolic enzyme in Escherichia coli. Proceedings of the National Academy of Sciences of the United States of America, 115(1), 222-227.

Maia, P., Rocha, M., \& Rocha, I. (2016). In silico constraint-based strain optimization methods: The quest for optimal cell factories. Microbiology and Molecular Biology Reviews, 80(1), 45-67. https://doi. org/10.1128/MMBR.00014-15

Masri, M. A., Garbe, D., Mehlmer, N., \& Brück, T. B. (2019). A sustainable, highperformance process for the economic production of waste-free microbial oils that can replace plant-based equivalents. Energy \& Environmental Science, 12(9), 2717-2732. https://doi.org/10.1039/C9EE00210C

Ndaba, B., Chiyanzu, I., \& Marx, S. (2015). N-Butanol derived from biochemical and chemical routes: A review. Biotechnology Reports, 8 , 1-9. https://doi.org/10.1016/j.btre.2015.08.001

Nielsen, D. R., Leonard, E., Yoon, S.-H., Tseng, H.-C., Yuan, C., \& Prather, K. L. J. (2009). Engineering alternative butanol production platforms in heterologous bacteria. Metabolic Engineering, 11(4), 262-273. https:// doi.org/10.1016/j.ymben.2009.05.003

Ohta, K., Beall, D. S., Mejia, J. P., Shanmugam, K. T., \& Ingram, L. (1991). Genetic improvement of Escherichia coli for ethanol production: Chromosomal integration of zymomonas mobilis genes encoding pyruvate decarboxylase and alcohol dehydrogenase I. Applied and Environmental Microbiology, 57(4), 893-900.

Ohtake, T., Pontrelli, S., Laviña, W. A., Liao, J. C., \& Putri, S. P. (2017). Metabolomics-driven approach to solving a CoA imbalance for improved 1-butanol production in Escherichia coli. Metabolic Engineering, 41, 135-143. https://doi.org/10.1016/j.ymben.2017.04.003

Park, J. H., Lee, K. H., Kim, T. Y., \& Lee, S. Y. (2007). Metabolic engineering of Escherichia coli for the production of L-valine based on transcriptome analysis and in silico gene knockout simulation. Proceedings of the National Academy of Sciences of the United States of America, 104(19), 7797-7802. https://doi.org/10.1073/pnas.0702609104

Park, S., \& Hahn, J. (2019). Development of an efficient cytosolic isobutanol production pathway in Saccharomyces cerevisiae by optimizing copy numbers and expression of the pathway genes based on the toxic effect of $\alpha$-acetolactate. Scientific Reports, February, 1-11. https://doi.org/10.1038/s41598-019-40631-5
Pasteur, L. (1862). Quelques résultats nouveaux relatifs aux fermentations acétique et butyrique. Bulletin de La Société Chimique de Paris, 52, 52-53.

Patakova, P., Linhova, M., Rychtera, M., Paulova, L., \& Melzoch, K. (2013). Novel and neglected issues of acetone-butanol-ethanol (ABE) fermentation by clostridia: Clostridium metabolic diversity, tools for process mapping and continuous fermentation systems. Biotechnology Advances, 31(1), 58-67. https://doi.org/10.1016/j.biotechadv.2012.01.010

Pfromm, P. H., Amanor-Boadu, V., Nelson, R., Vadlani, P., \& Madl, R. (2010). Bio-butanol vs. bio-ethanol: A technical and economic assessment for corn and switchgrass fermented by yeast or Clostridium acetobutylicum. Biomass and Bioenergy, 34(4), 515-524. https://doi.org/10.1016/j. biombioe.2009.12.017

Ranganathan, S., \& Maranas, C. D. (2010). Microbial 1-butanol production: Identification of non-native production routes and in silico engineering interventions. Biotechnology Journal, 5(7), 716-725. https://doi.org/10. 1002/biot.201000171

Reyes, L. H., Cardona, C., Pimentel, L., Rodríguez-López, A., \& AlmécigaDíaz, C. J. (2017). Improvement in the production of the human recombinant enzyme $\mathrm{N}$-acetylgalactosamine-6-sulfatase (rhGALNS) in Escherichia coli using synthetic biology approaches. Scientific Reports, 7(1), 1-14. https://doi.org/10.1038/s41598-017-06367-w

Rezaei, M., \& Zarkesh-Esfahani, S. H. (2012). Optimization of production of recombinant human growth hormone in Escherichia coli. Journal of Research in Medical Sciences, 17(7), 681-685.

Russmayer, H., Marx, H., \& Sauer, M. (2019). Microbial 2-butanol production with Lactobacillus diolivorans. Biotechnology for Biofuels, 12(1), 262. https://doi.org/10.1186/s13068-019-1594-5

Salis, H. M. (2011). Chapter two-The ribosome binding site calculator. In C. Voigt (Ed.), Methods in enzymology (498, pp. 19-42). London, UK: Academic Press. https://doi.org/10.1016/B978-0-12-385120-8.00002-4

Sauer, M. (2016). Industrial production of acetone and butanol by fermentation-100 years later. FEMS Microbiology Letters, 363(13), 1-4. https://doi.org/10.1093/femsle/fnw134

Schadeweg, V., \& Boles, E. (2016). Increasing n-butanol production with Saccharomyces cerevisiae by optimizing acetyl-CoA synthesis, NADH levels and trans-2-enoyl-CoA reductase expression. Biotechnology for Biofuels, 9(1), 1-11. https://doi.org/10.1186/s13068-016-0673-0

Shen, C. R., \& Liao, J. C. (2008). Metabolic engineering of Escherichia coli for 1-butanol and 1-propanol production via the keto-acid pathways. Metabolic Engineering, 10(6), 312-320. https://doi.org/10.1016/j. ymben.2008.08.001

Shen, C. R., Lan, E. I., Dekishima, Y., Baez, A., Cho, K. M., \& Liao, J. C. (2011). Driving forces enable high-titer anaerobic 1-butanol synthesis in Escherichia coli. Applied and Environmental Microbiology, 77(9), 2905-2915. https://doi.org/10.1128/AEM.03034-10

Sheridan, C. (2009). Making green. Nature Biotechnology, 27(12), 1074-1076. https://doi.org/10.1038/nbt1209-1074

Steen, E. J., Chan, R., Prasad, N., Myers, S., Petzold, C. J., Redding, A., \& Keasling, J. D. (2008). Metabolic engineering of Saccharomyces cerevisiae for the production of n-butanol. Microbial Cell Factories, 7, 36. https://doi.org/10.1186/1475-2859-7-36

Tian, P., Wang, J., Shen, X., Rey, J. F., Yuan, Q., \& Yan, Y. (2017). Fundamental CRISPR-Cas 9 tools and current applications in microbial systems. Synthetic and Systems Biotechnology, 2(3), 219-225. https:// doi.org/10.1016/j.synbio.2017.08.006

Trinh, C. T., Li, J., Blanch, H. W., \& Clark, D. S. (2011). Redesigning Escherichia coli metabolism for anaerobic production of isobutanol. Applied and Environmental Microbiology, 77(14), 4894-4904. https:// doi.org/10.1128/AEM.00382-11

Visioli, L. J., Enzweiler, H., Kuhn, R. C., Schwaab, M., \& Mazutti, M. a (2014). Recent advances on biobutanol production. Sustainable Chemical Processes, 2(1), 15. https://doi.org/10.1186/2043-7129-2-15

Viswanath, B. (2019). Recent developments in applied microbiology and biochemistry. Amsterdam, The Netherlands: Elsevier Science. 
https://www.elsevier.com/books/recent-developments-in-appliedmicrobiology-and-biochemistry/viswanath/978-0-12-816328-3

Wang, L., Dash, S., Ng, C. Y., \& Maranas, C. D. (2017). A review of computational tools for design and reconstruction of metabolic pathways. Synthetic and Systems Biotechnology, 2(4), 243-252. https://doi.org/10.1016/j.synbio.2017.11.002

Wang, Q., Ding, Y., Liu, L., Shi, J., Sun, J., Xue, Y., \& Xue, Y. (2015). Engineering Escherichia coli for autoinducible production of $\mathrm{n}$-butanol. Electronic Journal of Biotechnology, 18(2), 138-142. https://doi.org/10. 1016/j.ejbt.2015.01.003

Wang, X., Goh, E. B., \& Beller, H. R. (2018). Engineering E. coli for simultaneous glucose-Xylose utilization during methyl ketone production. Microbial Cell Factories, 17, 1-11. https://doi.org/10. 1186/s12934-018-0862-6

Watanabe, R., Doukyu, N., \& Bw, D. (2014). Improvement of organic solvent tolerance by disruption of the Ion gene in Escherichia coli. Journal of Bioscience and Bioengineering, 118(2), 139-144. https://doi. org/10.1016/j.jbiosc.2014.01.011

Wen, R. C., \& Shen, C. R. (2016). Self-regulated 1-butanol production in Escherichia coli based on the endogenous fermentative control. Biotechnology for Biofuels, 9, 267. https://doi.org/10.1186/s13068-0160680-1

Wess, J., Brinek, M., \& Boles, E. (2019). Improving isobutanol production with the yeast Saccharomyces cerevisiae by successively blocking competing metabolic pathways as well as ethanol and glycerol formation. Biotechnology for Biofuels, 12, 173. https://doi.org/10.1186/s13068-0191486-8

Wu, D., Wang, Q., Assary, R. S., Broadbelt, L. J., \& Krilov, G. (2011). A computational approach to design and evaluate enzymatic reaction pathways: Application to 1-butanol production from pyruvate. Journal of Chemical Information and Modeling, 51(7), 1634-1647. https://doi. org/10.1021/ci2000659

Xu, G., Wu, A., Xiao, L., Han, R., \& Ni, Y. (2019). Enhancing butanol tolerance of Escherichia coli reveals hydrophobic interaction of multi-tasking chaperone SecB. Biotechnology for Biofuels, 12, 164. https://doi.org/10.1186/s13068-019-1507-7
Yan, Q., \& Fong, S. S. (2017). Challenges and advances for genetic engineering of non-model bacteria and uses in consolidated bioprocessing. Frontiers in Microbiology, 8, 1-16. https://doi.org/10. 3389/fmicb.2017.02060

Yu, A., Alexandra, G., Skorokhodova, Y., \& Debabov, V. G. (2012). Metabolic engineering of Escherichia coli for 1-butanol biosynthesis through the inverted aerobic fatty acid b-oxidation pathway. Biotechnology Letters, 34), 463-469. https://doi.org/10.1007/s10529-011-0797-z

Zhang, W., Li, F., \& Nie, L. (2010). Integrating multiple "omics" analysis for microbial biology: Application and methodologies. Microbiology, 156(2), 287-301. https://doi.org/10.1099/mic.0.034793-0

Zhang, X., Jantama, K., Moore, J. C., Shanmugam, K. T., \& Ingram, L. O. (2007). Production of L-alanine by metabolically engineered Escherichia coli. Applied Microbiology and Biotechnology, 77(2), 355-366. https://doi.org/10.1007/s00253-007-1170-y

Zhao, C., Zhao, Q., Li, Y., \& Zhang, Y. (2017). Engineering redox homeostasis to develop efficient alcohol-producing microbial cell factories. Microbial Cell Factories, 16(1), 115. https://doi.org/10.1186/ s12934-017-0728-3

Zheng, Y. N., Li, L. Z., Xian, M., Ma, Y. J., Yang, J. M., Xu, X., \& He, D. Z. (2009). Problems with the microbial production of butanol. Journal of Industrial Microbiology and Biotechnology, 36(9), 1127-1138. https:// doi.org/10.1007/s10295-009-0609-9

Zhou, P., Zhang, Y., Wang, P., Xie, J., \& Ye, Q. (2014). Butanol production from glycerol by recombinant Escherichia coli. Annals of Microbiology, 64(1), 219-227. https://doi.org/10.1007/s13213-013-0654-5

How to cite this article: Ferreira S, Pereira R, Wahl SA,

Rocha I. Metabolic engineering strategies for butanol production in Escherichia coli. Biotechnology and Bioengineering. 2020;117:2571-2587. https://doi.org/10.1002/bit.27377 